\title{
Effects of intertrial interval and d-amphetamine on temporally organized behavior of pigeons
}

\author{
Lori Marie Lieving \\ West Virginia University
}

Follow this and additional works at: https://researchrepository.wvu.edu/etd

\section{Recommended Citation}

Lieving, Lori Marie, "Effects of intertrial interval and d-amphetamine on temporally organized behavior of pigeons" (2002). Graduate Theses, Dissertations, and Problem Reports. 697.

https://researchrepository.wvu.edu/etd/697

This Thesis is protected by copyright and/or related rights. It has been brought to you by the The Research Repository @ WVU with permission from the rights-holder(s). You are free to use this Thesis in any way that is permitted by the copyright and related rights legislation that applies to your use. For other uses you must obtain permission from the rights-holder(s) directly, unless additional rights are indicated by a Creative Commons license in the record and/ or on the work itself. This Thesis has been accepted for inclusion in WVU Graduate Theses, Dissertations, and Problem Reports collection by an authorized administrator of The Research Repository @ WVU. For more information, please contact researchrepository@mail.wvu.edu. 
Effects of intertrial interval and $d$-amphetamine on temporally organized behavior of pigeons

Lori M. Lieving

Thesis submitted to the Eberly College of Arts and Sciences

at

West Virginia University

In partial fulfillment of the requirements

for the degree of

\author{
Master of Arts \\ in \\ Psychology
}

David W. Schaal, Ph.D., Chair

B. Kent Parker, Ph.D.

Barry Edelstein, Ph.D.

Department of Psychology

\title{
Morgantown, West Virginia
}

2002

Keywords: timing, temporal discrimination, intertrial interval, $d$-amphetamine, drugs, stimulus value, pigeons 


\begin{abstract}
Effects of intertrial interval and $d$-amphetamine on temporally organized behavior of pigeons
\end{abstract}

Lori M. Lieving

The present experiment examined the effects of intertrial interval and $d$-amphetamine on pecking of pigeons maintained by an interval bisection task. The side-tracking group responded based on the location of the key and the color-tracking group responded based on the color of the key. Intermediate stimulus durations were tested, separated by either a 10- or 100-s intertrial interval and a range of $d$-amphetamine doses and saline were administered. Acquisition of performance in the side-tracking group occurred in fewer sessions relative to the color-tracking group. In both groups, the proportion of long responses increased as a function of stimulus duration. These functions were shifted to the left in the side-tracking group relative to the colortracking group. Increasing the intertrial interval shifted the functions to the right in the sidetracking group and did not affect performance in the color-tracking group. $d$-Amphetamine did not produce consistent effects on performance. 


\section{Acknowledgements}

I would like to extend my deepest gratitude to Dave Schaal for his contribution to this thesis. Dave spent a great deal of time and effort in the preparation of this document as well as the completion of the experiment. In addition, I would like to thank Dave for his contributions to my development as a graduate student and researcher. Dave was one of the first people that introduced me to behavior analysis and then welcomed me into his lab when I was looking to broaden my interests. He has been my advisor, teacher, colleague, and, most importantly, friend since I met him four and a half years ago. His contributions are not only evident in this document, but also in my growth as a behavior analyst. Thus, his impact on my life has been substantial and will certainly never be forgotten.

I would also like to thank my committee members, Kent Parker and Barry Edelstein, for their helpful suggestions and comments. Although the completion of the present experiment seemed impossible at times, both the proposal and defense of this thesis went smoothly because of their cooperation. They made beginning and finishing this project relatively painless.

Thanks are also due to my fellow graduate students (in particular Stephanie da Silva, Adam Doughty, Chad Galuska, Todd Knealing, and Tammy Wade). Their contributions include discussions of experimental and theoretical considerations as well as providing encouragement and offering advice throughout this project. They have been instrumental in my development as a researcher and, although we may disagree at times, I am honored to call them my friends.

I would also like to thank my family for their continued support for my alternative lifestyle as a graduate student. Although they joke that I will always be a "professional student," they have always supported my decisions and progress. Their unconditional support has allowed me to attend and succeed in graduate school. 
Last but not least, I would like to thank my husband, Gregory Lieving. He has impacted my life in countless ways, beginning with serving as my teacher and research supervisor. The first "gift" he ever gave me was "A Case History in Scientific Method" by B.F. Skinner. Since completing the requirements for his doctoral degree, Greg has lived four hours away. He has been more understanding than I thought one person could be. He has made the journey to Morgantown on countless weekends so I could run my birds, provided support for my progress through graduate school, and offered an ear when I needed to rant about anything. The completion of this project would not have been possible without his support. I am thankful for every day that he continues to be a part of my life as my husband and colleague. 


\section{List of Figures}

Page

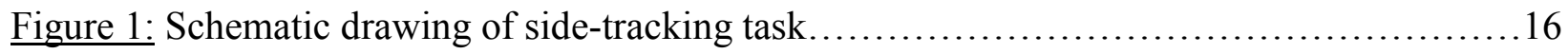

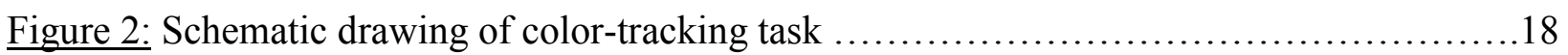

Figure 3: Differences between proportion of long responses for side-tracking group during test and drug sessions.

Figure 4: Differences between proportion of long responses for color-tracking group during test and drug sessions

Figure 5: Differences between latencies to initiate trials for side-tracking group during test and

drug sessions.

Figure 6: Differences between latencies to initiate trials for color-tracking group during test and

drug sessions. 


\section{List of Tables}

Page

Table 1: Order of conditions for each group of subjects................................ 13

Table 2: Number of sessions required to meet stability criterion for each group of subjects......23

Table 3: Means and standard deviations of the parameters of logistic functions fitted to the data

from individual pigeons for the side-tracking group............................ 31

Table 4: Means and standard deviations of the parameters of logistic functions fitted to the data

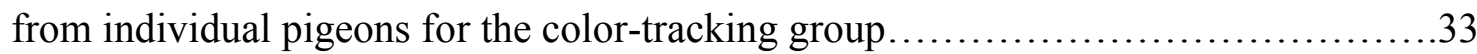




\section{Table of Contents}

Page

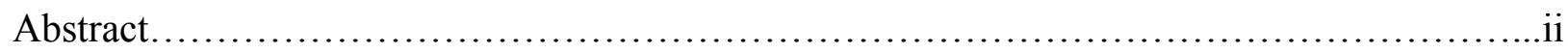

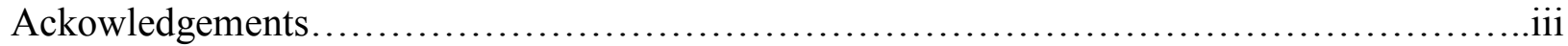

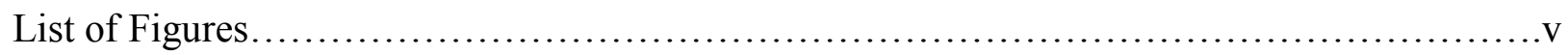

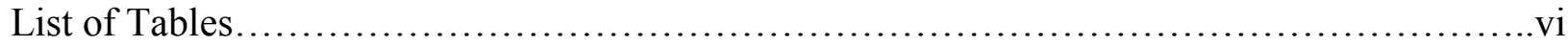

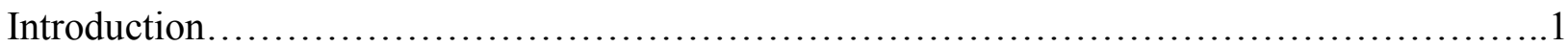

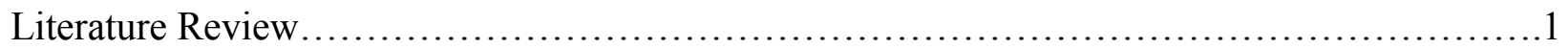

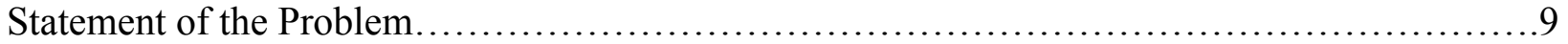

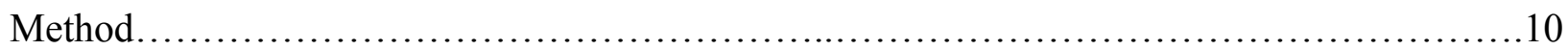

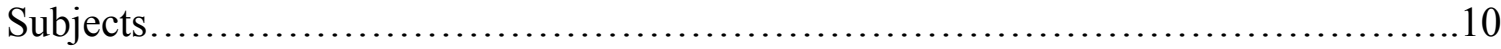

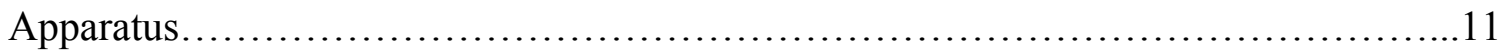

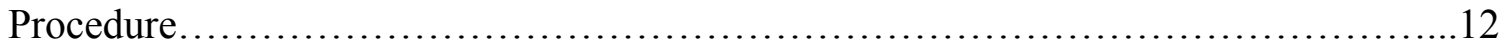

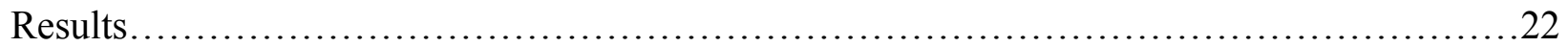

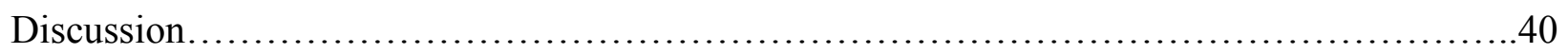

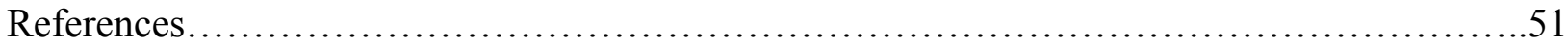




\section{Introduction}

In this experiment, two variables that enhance the value of stimuli correlated with food reinforcement were varied separately and in combination to determine their effects on pigeons' discrimination of temporal stimuli. One variable was the time between presentations of the stimulus, or, in this experiment, the intertrial interval (ITI). The value of stimuli signaling impending food has been shown in various procedures to be a direct function of the ITI duration (e.g., Santi, Coyle, Coppa, \& Ross, 1998). The question posed by the present experiment was whether changes in stimulus value produced by changes in the ITI alter discrimination of the duration of the timing stimulus. The other variable was $d$-amphetamine, which has been shown to enhance the conditioned reinforcing value of food-correlated stimuli (e.g., Mazurski \& Beninger, 1986). In addition, $d$-amphetamine causes animals to overestimate the duration of stimuli (Maricq, Roberts, \& Church, 1981; Meck, 1983), so the primary question addressed by the present experiment was whether $d$-amphetamine alters discrimination of the duration of a stimulus by increasing stimulus value. Finally, because estimates of temporal discrimination depend critically on the type of task employed, two variations on the interval-bisection task, which impose slightly different behavioral contingencies on the same temporal discrimination, were tested in separate groups of pigeons.

\section{Literature Review}

This review will describe the findings typically observed when behavior is maintained by an interval bisection task and how those findings relate to temporal discrimination. The discussion will then focus on the role of the stimulus value in the timing of a stimulus. Finally, the typical effects of drugs on temporally organized behavior will be described. 
One method to assess temporal discrimination, or "timing," in animals is the interval bisection task. Church and Deluty (1977) trained rats to respond on one lever after a "short" stimulus and another lever after a "long" stimulus. Stimulus durations ranged from $1-16 \mathrm{~s}$ and the long stimulus was typically four times longer than the short stimulus. Once responding was stable, intermediate stimulus durations were introduced on probe trials (i.e., test trials in which no reinforcement occurred). The five intermediate durations were equal logarithmic units between the extreme durations. For example, when the short stimulus was $2 \mathrm{~s}$ and the long stimulus was $8 \mathrm{~s}$, the intermediate values were $2.6,3.2,4,5$, and $6.4 \mathrm{~s}$. The proportion of long responses, the total number of long responses occurring during each trial type divided by the total number of trials for each type, were then plotted as a function of stimulus duration. An Sshaped function was observed indicating that the probability of a long response occurring after a short stimulus was low and gradually increased as the stimulus duration increased. The point at which the proportion of long responses was .50 approximated the geometric mean of the two temporal endpoints (i.e., the square root of the product of the duration extremes; the bisection point for 2- and 8-s stimuli would be $4 \mathrm{~s}$ while the midpoint for 1 and $4 \mathrm{~s}$ would be 2).

In the interval bisection task, responding on either the short or the long alternative is primarily a function of the duration of the temporal stimulus. Other variables, however, have been shown to alter the discrimination of the temporal stimuli. More specifically, variables that alter the value of the temporal stimulus also alter the discrimination of that stimulus. The term value, for present purposes, refers to a property of a stimulus that is indicated by the relative vigor with which it is tracked or attended to, responded to, worked for, or remembered. Generally, a stimulus acquires value by virtue of its relation to positive reinforcers. Through classical conditioning, for example, a conditioned stimulus (CS) may be reliably paired with an 
unconditioned stimulus (US) that elicits an unconditioned response (UR). The magnitude of a resulting conditioned response (CR) may indicate the value of the CS. In operant conditioning, a stimulus may have value because it signals the opportunity for reinforcement to occur. Such stimuli are called discriminative stimuli, or $\mathrm{S}^{\mathrm{D}}$, $\mathrm{s} . \mathrm{S}^{\mathrm{D}}$, $\mathrm{s}$ which signal high rates of reinforcement have relatively higher stimulus value than $\mathrm{S}^{\mathrm{D}}$, that signal lower rates of reinforcement. Finally, stimuli that are predictive of reinforcing stimuli may become conditioned reinforcers. Rates of responding leading to the presentation of such stimuli could provide an index of their value. The rest of this literature review will focus on other variables that alter the value of a stimulus and how, in turn, the timing of that stimulus is altered.

One variable that has been shown to alter the value of a stimulus in classical conditioning is its correlation with a US (Gibbon, Locurto \& Terrace, 1975; Rescorla, 1968). Rescorla (1968) examined the effects of different probabilities of presenting the US in the absence of a CS on conditioned suppression in rats. Bar pressing was maintained on a variable-interval (VI) 2-min schedule of reinforcement (i.e., bar pressing was reinforced on the average of every $2 \mathrm{~min}$ ). Ten groups of rats experienced different probabilities of shock presentation during a 720-cps tone. The shock was presented an equal number of times in both the presence and absence of the tone, more often in the presence of the tone than in the absence of the tone, or only in the presence of the tone. When suppression ratios were examined, it was clear that the most suppression occurred when there was a low probability of shock being delivered in the absence of the tone.

Altering the value of temporal through classical conditioning can alter the discrimination of those stimuli (Holder \& Roberts, 1985; Kirkpatrick \& Church, 1998; Roberts \& Holder, 1985). Roberts and Holder (1985), for example, investigated how modifying the signal value of a temporal stimulus affected the timing of that stimulus by rats. At the beginning of each trial, 
the houselight was extinguished for either 3 or $12 \mathrm{~s}$. Once the test duration had elapsed, two response levers were inserted into the chamber. Responses on one lever were reinforced when preceded by the 3-s stimulus ("short" stimulus) and responses on the other lever were reinforced when preceded by the 12-s stimulus ("long" stimulus). During interspersed conditioning trials, the houselight was turned off for $15 \mathrm{~s}$. After this time had elapsed, trials either ended with food presentation (Pairing trials) or without food presentation (Extinction trials). Short bias, a measure reflecting the difference between accuracy on short and long trials, differed across pairing and extinction trials. Specifically, during extinction trials, short bias increased, suggesting that there was a lower tendency to choose long. In other words, responding occurred as though less time had passed than actually had. Roberts and Holder (1985) concluded, "decreasing the signal value of a stimulus decreases the timing of the stimulus" (Roberts \& Holder, 1985, p. 198).

Another variable that has been shown to alter the value of a stimulus is the reinforcement rate in its presence. Nevin, Mandell, and Atak (1983) attempted to disrupt behavior maintained by different VI schedules of reinforcement in pigeons. Responding was maintained on a multiple schedule in which green and red key lights signaled different VI schedules (which arranged 129,42 , or 10 reinforcers per hour) and the red key was always associated with the higher rate of reinforcement and therefore had greater value. The multiple schedule alternated with periods in which the keys were dark and food was delivered according to a variable-time (VT) schedule of reinforcement in which food was delivered response independently (i.e., arranged $60,120,180$, or 300 reinforcers per hour). These dark-key reinforcers were intended to disrupt rates of pecking when the keys were lit. As the number of reinforcers delivered during dark-key periods increased, response rates in the presence of both green and red keys decreased. 
Responding in the presence of the red key, the key that was associated with a higher rate of reinforcement, was more resistant to the effects of the free food deliveries than responding maintained during the green key. Therefore, responding maintained in the presence of the red key could be said to be more resistant to disruption.

It has also been shown that the rate of reinforcement associated with a temporal stimulus can alter the discrimination of that stimulus. Morgan, Killeen, and Fetterman (1993) examined the effect of the rate of reinforcement associated with a temporal stimulus on the timing of that stimulus. After training on an interval bisection task using the presentation of a red keylight for 10 or $20 \mathrm{~s}$, reinforcement probability was reduced to 0.25 and, on $25 \%$ of the trials, a 14 -s stimulus was presented. Responding after the 14-s stimulus was not reinforced (i.e., it was a probe test) and was used as a measure of temporal discrimination. Because $14 \mathrm{~s}$ was the temporal midpoint of the two trained stimuli (i.e., 10 and 20 s), it was expected that responding after both stimulus durations would be distributed evenly during the 14-s stimulus presentation. Therefore, any deviations from $50 \%$ would indicate changes in temporal discrimination. Following this training, the interval bisection trials were discontinued and half of the subjects were exposed to a low rate of free reinforcers in the presence of the red keylight while the other half of the subjects experienced a high rate of free reinforcers. Subjects then responded on a modification of the baseline task, in which half of the trials consisted of the 14-s stimulus while the other half of the trials consisted of either the 10- or 20-s stimulus, but no reinforcement was delivered. The probability of responding "long" after the 14-s stimulus was compared between the groups. When subjects had a history of a higher rate of free reinforcers, there was an increased tendency to respond on the long key after the 14-s stimulus. Conversely, when subjects had a history of a lower rate of free reinforcers, there was a decreased tendency to 
respond on the long key. Thus, when a higher rate of reinforcer delivery was associated with the temporal stimulus, subjects responded as though more time had passed. It could be argued that altering the reinforcement rate associated with the temporal stimulus altered the value of the stimulus, therefore changing the timing of that stimulus.

Another factor that could affect the value of a stimulus is the ITI. Increasing the ITI often increases the associative value of a CS (Kaplan, 1984; Oberdieck, Cheney, \& Mueller, 1978; Terrace, Gibbon, Farrell, \& Baldock, 1975). Kaplan (1984) assessed the conditioned inhibitory and excitatory status of a CS in an autoshaping procedure. Trials were separated by ITI's of $15,30,60,120$, or $240 \mathrm{~s}$ across groups of pigeons. A response key was lit green for $12 \mathrm{~s}$ and then, after a 12-s interval, food was presented. Stronger approach responses to the CS were observed at longer ITI's (120 or 240 s) while shorter ITI's (15 or 30 s) produced withdrawal responses from the CS. The increase in approach responses showed that the excitatory function of the CS was greater with long ITI's.

Increasing the ITI has also been shown to alter the timing of stimuli (Raslear, Shurtleff, \& Simmons, 1992; Santi, Coyle, Coppa, \& Ross, 1998). Santi, Coyle, Coppa, and Ross (1998) trained pigeons to respond on the interval bisection task (Church \& Deluty, 1977), in which either a 2- (short) or 8-s (long) stimulus was presented (either a tone or light). After training with a 10 -s ITI, the ITI was varied $(4,8,16$, or $32 \mathrm{~s})$. When the temporal stimulus was a light, very little change in performance was observed as a function of ITI. On the other hand, when the temporal stimulus was a tone, there was an increased tendency to choose the long alternative when the ITI was long. Similarly, Raslear, Shurtleff, and Simmons (1992) trained rats to respond on an interval bisection procedure in which either a 0.1 - or 10-s houselight was 
presented. After training with an ITI of $5 \mathrm{~s}$, the ITI was varied $(1,2.5,5,10$, or $20 \mathrm{~s})$. Increasing the ITI increased the tendency to respond on the long key.

Some drugs, in particular psychomotor stimulants, are also thought to enhance the value of stimuli associated with reinforcement (Mazurski \& Beninger, 1986, Robbins, 1978; Robbins, Watson. Gaskin, \& Ennis, 1983). Mazurski and Beninger (1986) evaluated the effects of (+)amphetamine and apomorphine on responding of rats maintained by conditioned reinforcement. During the preexposure phase, responding on one lever produced a 3-s tone and responding on the other lever turned the light in the chamber off for $3 \mathrm{~s}$. During the conditioning phase, the light-off stimulus was paired with food response independently, initially after every stimulus presentation and eventually on only $33 \%$ of the trials. Testing consisted of conditions similar to the preexposure phase in that responding was followed by the presentation of either the 3-s tone or 3-s light offset. A range of doses of (+)-amphetamine $(0.13,0.25,0.5,1.0,2.0$, and 4.0 $\mathrm{mg} / \mathrm{kg})$ and apomorphine $(0.06,0.13,0.5,0.75$, and $1.0 \mathrm{mg} / \mathrm{kg})$ were administered prior to either the conditioning sessions or the testing sessions. Under no-drug conditions, response rates were higher on the lever that produced the light-off stimulus than on the lever that produced the 3-s tone. When $(+)$-amphetamine was administered during conditioning, a dose-dependent decrease in response rates was observed. Similarly, when apomorphine was administered, either during conditioning or during testing, response rates either remained close to control levels of responding or decreased in a dose-dependent manner. When $(+)$-amphetamine was administered during test conditions, however, responding that was maintained by the light-off stimulus markedly increased at moderate doses of the drug (i.e., $0.5,1.0$, and $2.0 \mathrm{mg} / \mathrm{kg}$ ). These results are consistent with the notion that the administration of $(+)$-amphetamine during testing conditions enhanced the conditioned-reinforcing effects of the light-off stimulus. 
Robbins, Watson, Gaskin, and Ennis (1983) also reported the enhancing effect of $d$ amphetamine on responding maintained by the delivery of stimuli associated with water delivery to water-deprived rats. During training, water was paired with a light and the noise of the water dipper. Water delivery occurred on a random-time schedule of 30 s (RT 30 s), in which water delivery occurred response independently, on average, every $30 \mathrm{~s}$. Following training, pressing one of two levers in the chamber (the CR lever) produced the stimuli that had been previously associated with water delivery on a random-interval schedule of $5 \mathrm{~s}$ (RI $5 \mathrm{~s}$ ), but water delivery no longer occurred. Pressing the other lever (the NCR lever) had no effect. Under control conditions, responding on the $\mathrm{CR}$ lever occurred at a higher rate relative to responding on the NCR lever. After a range of doses of $d$-amphetamine $(0.25,0.5,1.0,1.9,2.9 \mathrm{mg} / \mathrm{kg})$ was administered, responding on the CR lever increased while responding on the NCR lever either stayed the same as responding under control conditions or decreased. These results are also consistent with the notion that $d$-amphetamine increased the efficacy of conditioned reinforcers.

Pairing stimuli with food, increasing the rate of reinforcement associated with stimuli, or increasing the ITI, enhance the value of stimuli. When stimulus value is increased, the discrimination of those stimuli is altered, resulting in responding occurring as though more time has passed than actually has (or "jumping the gun"). Stimulant administration has also been shown to increase the value of conditioned reinforcing stimuli. In addition, stimulant administration produces an overestimation of temporal stimuli. Perhaps these drugs alter the timing of stimuli because they alter the value of those stimuli.

In a study of the effects of methamphetamine on temporally organized behavior, Meck (1983) trained rats on an interval bisection procedure using 2- and 8-s stimuli. One group of rats received saline prior to training sessions while the other group of rats received 
methamphetamine. The probability of a long response was low after short stimuli and increased as stimuli duration increased for both groups. When testing began, subjects that were trained with methamphetmine were given saline and subjects that were trained with saline received methamphetamine. The onset of methamphetamine produced a leftward shift in the function relating proportion of long responses to stimulus duration (hereafter referred to as the timing function) while the cessation of methamphetamine produced a rightward shift in the function. It was suggested that methamphetamine increased the rate of an internal pacemaker, which resulted in an overestimation of time. Similarly, the rightward shift associated with the cessation of drug administration was said to be caused by a decrease in the rate of the pacemaker, producing an underestimation of time.

Similarly, Bizot (1997) examined the effects of drugs from several pharmacological classes on responding maintained by the interval bisection task in rats. Subjects were trained to discriminate presentations of either 5- or 20-s stimuli. Amphetamine shifted the timing functions to the left. This finding is consistent with an overestimation of time. Thus, in several studies (e.g., Bizot, 1997, Kraemer, Randall, Dose \& Brown, 1997; Maricq, Roberts, \& Church, 1981; Maricq \& Church, 1983; Meck, 1983) it has been shown that psychomotor stimulants alter temporal discrimination in a similar manner to increases in the value of the timed stimulus (i.e., both cause an overestimation of elapsed time).

\section{Statement of the Problem}

When the ITI is increased or psychomotor stimulants are administered, overestimations of time have been obtained. Whether these two variables produce an overestimation of time by similar processes (i.e., by altering the value of the temporal stimulus), however, remains unclear. The present experiment examined the effects of ITI and $d$-amphetamine alone and in 
combination. If increasing the ITI and administering $d$-amphetamine affect temporal discrimination similarly, then altering both variables at the same time should enhance the leftward shift in the timing function that are obtained when the variables are altered alone. Thus, producing enhanced leftward shifts in timing functions would provide some insight into whether these variables affect temporally organized behavior by affecting the same behavioral mechanism.

The discrimination of a temporal stimulus also depends on the characteristics of the task. Observations in our laboratory of pigeons responding on an interval bisection task that arranged for pecks on the left key to be reinforced after a 2-s houselight and pecks on the right key to be reinforced after an 8-s houselight revealed a clear behavioral pattern. At the onset of a trial, subjects would stand in front of the left key for approximately $2 \mathrm{~s}$ and then move to the right key. It could be argued that, in this procedure, the temporal discrimination is based on behavior (i.e., switching from left to right) that is governed by whether or not $2 \mathrm{~s}$ has passed, rather than based on a comparison of the two stimuli. The results obtained from a procedure like this could be considerably different from results obtained from a procedure that requires that the discrimination be based on a comparison of both stimuli. Therefore, two tasks which require the same temporal discrimination but different behavioral contingencies were used. One group of pigeons responded either to the left or right key and another group of pigeons were trained to respond on yellow or red stimuli that were presented randomly on either of the side keys.

Method

\section{Subjects}

The subjects were 6 adult male White Carneau pigeons. Upon arrival at the animal colony, pigeons were allowed free access to food for 2 weeks. Once daily weights were stable, 
access to food was restricted so that weights were reduced to $80 \%$ of free-feeding weight over a

2-week period. Pigeons were maintained at $80 \%$ free-feeding weight through post-session feedings as necessary. When not in experimental sessions, pigeons were individually housed in a temperature-controlled colony under a 12:12 hr light:dark cycle with free access to water and health grit.

Apparatus

Four custom-made experimental chambers constructed of wood with aluminum front panels were used. Each chamber was $33 \mathrm{~cm}$ wide, $31 \mathrm{~cm}$ from front to back, and $37.5 \mathrm{~cm}$ high. Three response keys were mounted $26 \mathrm{~cm}$ from the floor on the front panels. The keys could be lit from behind with various colors and required a force of approximately $0.19 \mathrm{~N}$ to record a response. A 28-V 1.1-W lamp $7 \mathrm{~cm}$ above the center key served as the houselight. A rectangular aperture $16 \mathrm{~cm}$ below the center key provided access to a solenoid-operated food hopper. Photocells located on each side of the hopper aperture detected latencies to hopper entry. During hopper presentations, the aperture was lit with white light, and the houselight and keylights were extinguished. A Radio Shack@ Indoor Security Camera Model 49-2512 was mounted $34 \mathrm{~cm}$ from the floor and $17 \mathrm{~cm}$ from the front of the chamber on the back wall of each chamber during control and test sessions. The video camera was connected to a Zenith $\odot$ 4-Head VHS videocassette recorder and a UNIC@ 5-in black and white television Model RV-TVR5 to record experimental sessions. Extraneous sounds were masked by white noise and chamber ventilation fans. Contingencies were programmed and data collected by microcomputers located in an adjacent room. 


\section{Procedure}

Pretraining.

Experimentally-naïve pigeons (Pigeons 128, 492, and 789) were acclimated to the chambers and then trained to eat from the food hopper. Based on pigeons' latency to place their head in the hopper (i.e., break the photocell beam inside the hopper aperture), a computer program gradually decreased the hopper duration and increased the time between hopper presentations as the pigeons placed their heads in the hopper more rapidly. Sessions terminated following 40 hopper presentations. When pigeons reliably placed their heads in the hopper with short latencies after the hopper was raised, key pecks were autoshaped (Browns \& Jenkins, 1968). During autoshaping, after a varying amount of time averaging $60 \mathrm{~s}$, a key was lit red, yellow, green, or white for $6 \mathrm{~s}$ followed by presentation of the hopper for $4 \mathrm{~s}$. Pecks to a lit key resulted in immediate hopper presentation. The key colors were presented in random order 10 times for a total of 40 hopper presentations. Autoshaping continued until pigeons reliably and with short latencies pecked all key color and position combinations necessary for the experiment.

Following autoshaping, key pecking was reinforced on a fixed-ratio (FR) 1 schedule of reinforcement for a minimum of three sessions. Sessions terminated after 40 reinforcer presentations and continued until pigeons reliably responded. Once responding was consistently maintained on the FR 1 schedule, the interval bisection procedure was presented. Table 1 shows the different types of conditions and the order of exposure for each group. Reinforcers consisted of 3-s access to grain and sessions were conducted $6-7$ days a week at approximately the same time of day.

\section{Training on the Interval-Bisection Task.}

Following a 10-min blackout, the center key was lit white and a peck to the key produced 
Table 1

Order of conditions (task, sessions, ITI duration, and whether drug will be administered) for each group of subjects.

\begin{tabular}{lllll}
\hline Group & Task & Session & ITI duration & Drug Testing \\
& & & \\
\hline & & & \\
& Side tracking & Training & $10 \mathrm{~s}$ & No \\
& Side tracking & Test & $10 \mathrm{~s}$ & No \\
& Side tracking & Test & $100 \mathrm{~s}$ & No \\
& Side tracking & Test & $10 \mathrm{~s}$ & No \\
& Side tracking & Test & $10 \mathrm{~s}$ & Yes \\
& Side tracking & Test & $100 \mathrm{~s}$ & Yes \\
& & & No \\
& Color tracking & Training & $10 \mathrm{~s}$ & No \\
& Color tracking & Test & $10 \mathrm{~s}$ & No \\
Color tracking & Test & $100 \mathrm{~s}$ & No \\
Color tracking & Test & $10 \mathrm{~s}$ & Yes \\
Color tracking & Test & $10 \mathrm{~s}$ & Yes \\
Color tracking & Test & $100 \mathrm{~s}$ & \\
\hline
\end{tabular}

Note. Training sessions refer to sessions in which only the training stimulus durations are present ( 2 and $8 \mathrm{~s}$ ). Test sessions refer to sessions in which training and test stimulus durations are present $(2.0,2.6,3.2,4.0,5.0,6.4$, and $8.0 \mathrm{~s})$. 
4-s access to grain. After the hopper presentation, a 10-s ITI began (i.e., all key lights and houselight were extinguished). At the end of each ITI, the center key was lit white and one peck to the center key began the next trial. If no response was made within $15 \mathrm{~s}$, the center key light was extinguished and the trial began. At the onset of the trial, the houselight was lit for either 2 or $8 \mathrm{~s}$. Once the duration had elapsed, the left and right keys were lit.

Three pigeons $(481,112$, and 393) were trained on the side-tracking task. In this task, both side keys were lit green and a peck to left key after the 2-s stimulus (short stimulus) was presented was followed by grain and a peck to the right key was reinforced after the 8-s stimulus (long stimulus) was presented (see Figure 1). If no response occurred within $30 \mathrm{~s}$ of the keys being lit, the trial ended and the ITI began. After a correct response, all lights were extinguished and the hopper was presented for $3 \mathrm{~s}$, followed by the ITI. After incorrect responses, all lights were extinguished for $3 \mathrm{~s}$ and then the ITI began (i.e., there were no correction trials). The duration of the stimulus was randomly selected, with the restriction that the same duration could not be presented more than three consecutive times.

Three other pigeons $(128,492$, and 789$)$ were trained on the color-tracking task. In this task, pecks to the yellow key were reinforced after the 2-s stimulus was presented and pecks to the red key were reinforced after the 8-s stimulus was presented (see Figure 2). If no response occurred within $30 \mathrm{~s}$ of the keys being lit, the trial ended and the ITI began. The location of the yellow and red keys varied unpredictably from trial to trial, with no more than 3 consecutive trials in which the colors appeared on the same keys. After a correct response, all lights were extinguished and the hopper was presented for $3 \mathrm{~s}$, followed by the ITI. Initially, after an incorrect response, all lights were extinguished for $3 \mathrm{~s}$ and then the ITI began (i.e., there was no correction procedure). After approximately 30 sessions, a correction procedure was added 
Figure 1 (next page). Schematic drawing representing a trial during the side-tracking task. Horizontal dashed lines indicate different portions of the trial. Solid circles indicate the response keys. Darkened circles indicate inoperative keys. Dashed circles indicate the houselight. The G indicates the keys will be lit with a green light. 


\section{Beginning of Session}
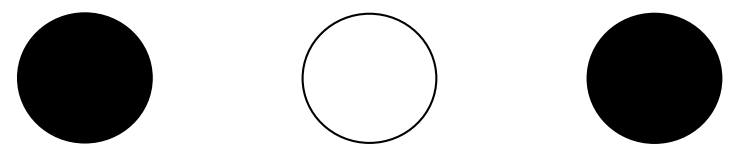

Center Key - FR 1

ITI - 10 or $100 \mathrm{~s}$

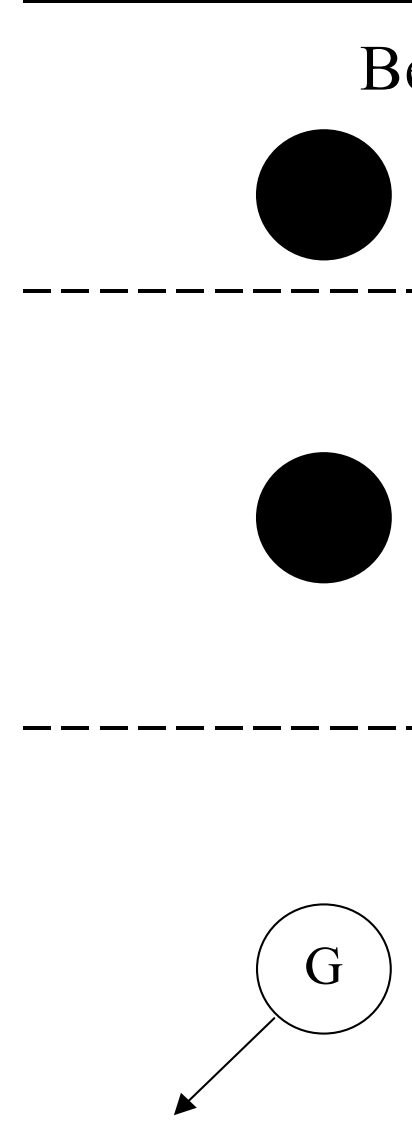

Beginning of Trial
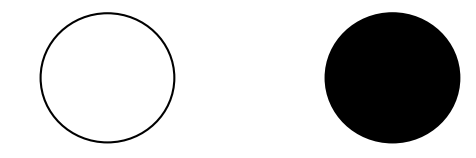

Trial-Ready Key

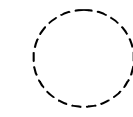

Houselight Presentation
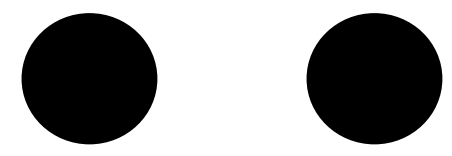

Training Durations ( 2 or $8 \mathrm{~s}$ ) Testing Durations $(2,2.6,3.2,4,5,6.4$, or $8 \mathrm{~s})$

Left key pecks reinforced if preceded by 2 -s stimulus
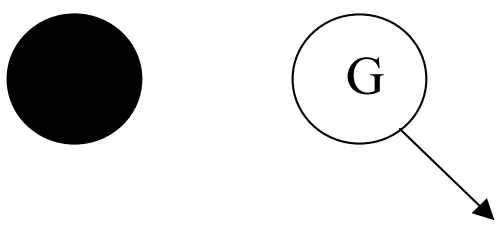

Right key pecks reinforced if preceded by 8 -s stimulus

3-s hopper presentation or 3-s blackout

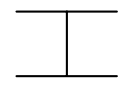

ITI -10 or $100 \mathrm{~s}$ 
Figure 2 (next page). Schematic drawing representing a trial during the color-tracking task. Horizontal dashed lines indicate different portions of the trial. Solid circles indicate the response keys. Darkened circles indicate inoperative keys. Dashed circles indicate the houselight. The R and $\mathrm{Y}$ indicate the keys will be lit with red and yellow lights, respectively. 


\section{Beginning of Session}
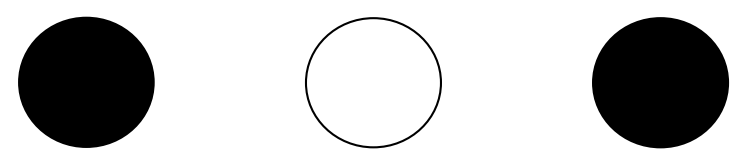

Center Key - FR 1

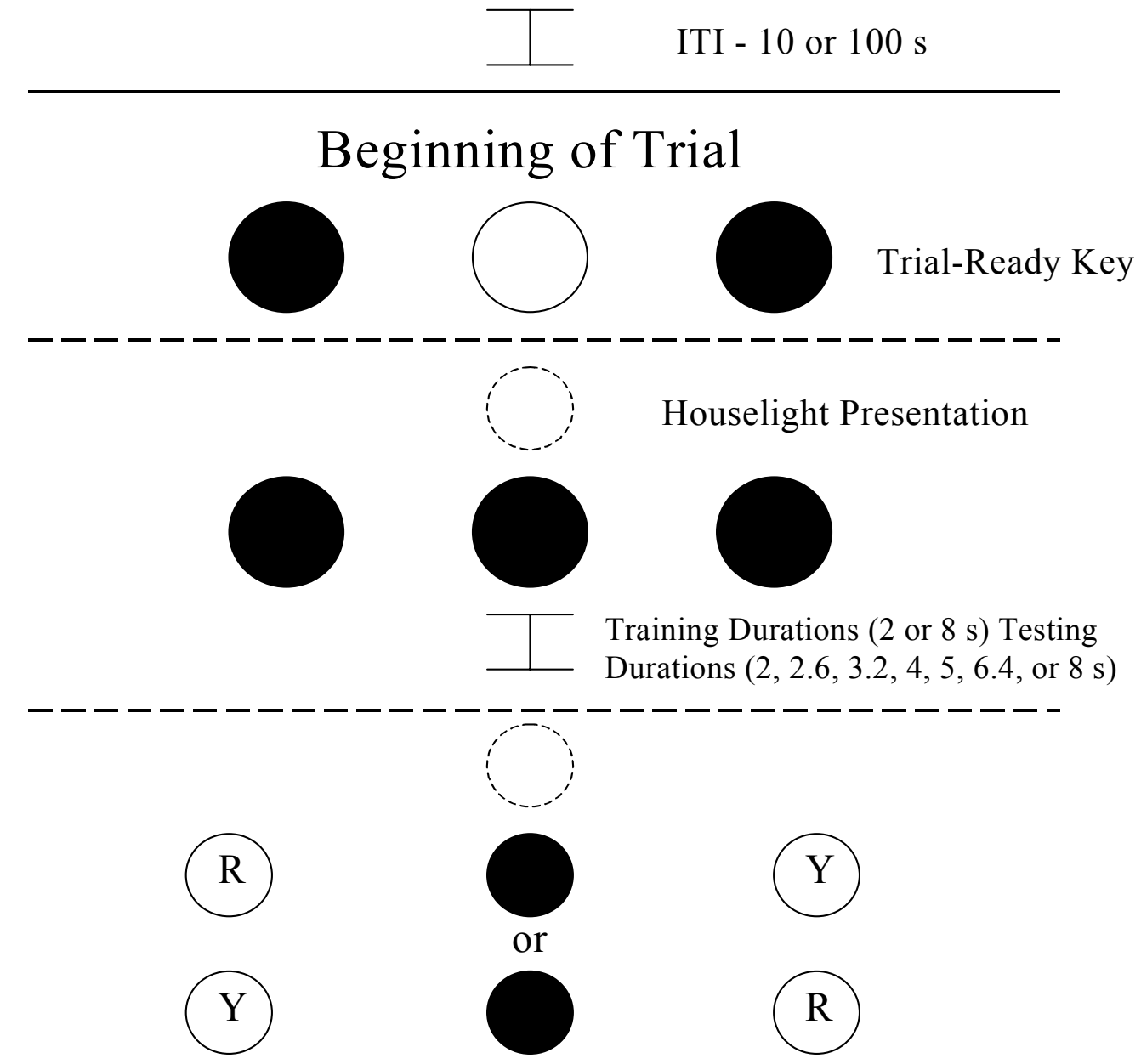

ITI -10 or $100 \mathrm{~s}$

Yellow key pecks reinforced

Red key pecks reinforced if if preceded by 2 -s stimulus preceded by 8 -s stimulus

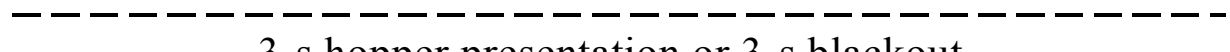

3-s hopper presentation or 3-s blackout

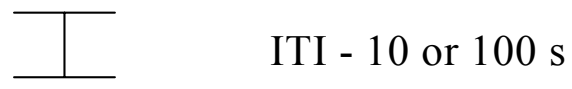


because correct responses occurred on only half of the trials, which indicated that the pigeons had not yet learned the discrimination. After an incorrect response, all lights were extinguished and the ITI began. The trial in which an incorrect response occurred was repeated until the correct response occurred. Responding during correction trials was not included in the data analysis.

Two additional modifications of the color-tracking task were necessary in order for responding to meet the stability requirement. First, during the houselight stimulus presentation, pigeon 492 pecked the dark, right key. After the stimulus duration elapsed, the keys were lit and most of this birds responses occurred on the right key, regardless of the sample duration or key color. In order to eliminate pecking the dark key, a contingency was added so that pecking the key when it was not lit ended the trial and began a correction trial. Correction trials were presented until no dark key pecking occurred and a correct response occurred. Second, pigeon 789 would not peck the center white key to begin the trials. In order to increase pecking, the houselight was turned on while the center key was lit. When a key peck to the center key occurred, the center key light was extinguished and the houselight flashed off for $.1 \mathrm{~s}$ to signal the start of the timing stimulus.

Sessions ended after 60 trials and lasted approximately 30-40 minutes. The proportion of "long" responses (the number of long responses divided by the total number of either short or long trials) was calculated for each trial type. Once the proportion of long responses was greater than .8 for long trials and less than .2 for short trials and showed no increasing or decreasing trends, as judged by visual inspection, the probability of reinforcement was reduced to .50 . During the side-tracking task, reinforcers were delivered after a correct response on 15 of the trials with an 8-s stimulus and 15 of the trials with a 2-s stimulus. During the color-tracking task, 
correct responding was reinforced on long and short trials half of time when the yellow stimulus was on the left and half of the time when the yellow stimulus was on the right. Once responding was stable, testing sessions began.

\section{Testing - Intermediate Stimulus Durations.}

During test sessions with intermediate stimulus durations, test trials were intermixed with training trials ( 2 or 8 -s stimulus duration). During test trials, one of a range of stimulus durations was presented $(2.0,2.6,3.2,4.0,5.0,6.4$, and $8.0 \mathrm{~s})$. Responses occurring during test trials were counted, but no reinforcement was delivered (i.e., responses were followed by 3 -s blackout and ITI). Probe trials were conducted during all testing conditions to avoid any habituation to the testing procedure. In the side-tracking task, each test duration was presented five times and the training durations ( 2 and $8 \mathrm{~s}$ ) were presented either 12 or 13 times (this number alternated each test session). In the color-tracking task, each test duration was present four times, two times in which the left key was yellow and the right key was red and two times in which the conditions were reversed. Training durations ( 2 and $8 \mathrm{~s}$ ) were presented ten times each, five times in which the left key was yellow and the right key was red and five times in which the conditions were reversed. Trial types and stimulus durations were randomly selected with the restriction that the same duration or type (i.e., training or test) could not be presented more than three consecutive times. Side-tracking test sessions ended after 60 trials (35 test trials and 25 training trials) and color-tracking test sessions ended after 48 trials (28 test trials and 20 training trials) and lasted approximately 30 - 40 minutes. At least three control sessions separated sessions with test trials. All control and test sessions were videotaped via the security camera mounted in the back of the chamber. Test sessions with the 10-s ITI were repeated three times.

\section{Testing - Intermediate Stimulus Durations and Increased ITI Duration.}


Once responding was stable during sessions with test trials, the ITI was increased from $10 \mathrm{~s}$ to $100 \mathrm{~s}$. All other conditions were as described above with the exception of the session duration. Because of the 90-s increase in the ITI, sessions lasted approximately two hours. At least three control sessions separated test sessions. Test sessions with the 100-s ITI were repeated three times.

\section{Drug Administration.}

Pigeons experienced at least 65 sessions of the interval-bisection procedure (range 65 171) prior to administration of $d$-amphetamine. Drug testing began when the proportion of long responses was stable as determined by visual inspection (i.e., there were no trends or extreme variability over the last $15-20$ sessions). A range of doses of $d$-amphetamine $(0.3,0.56$, and 1.0 $\mathrm{mg} / \mathrm{kg}$ ) were dissolved in $.09 \%$ saline and administered in a volume of $1.0 \mathrm{ml} / \mathrm{kg}$. Injections were delivered into the breast muscle immediately before pigeons were placed in the chambers. $d$-Amphetamine and the vehicle were administered prior to test sessions in ascending (saline, 0.3, $0.56,1.0 \mathrm{mg} / \mathrm{kg})$, descending $(1.0,0.56,0.3 \mathrm{mg} / \mathrm{kg}$, saline $)$, and then ascending order. A test session with each ITI (10 and $100 \mathrm{~s}$ ) was conducted at each dose before proceeding to the next dose (e.g., saline with 10-s ITI, saline with 100-s ITI). Dose-effect curves were determined completely before any dose was repeated. Pigeons were weighed prior to and after experimental sessions, and tests were not conducted if initial weights were not within $10 \mathrm{~g}$ of the $80 \%$ weight. After the completion of three determinations of each dose of $d$-amphetamine, two additional doses $(1.7$ and $3.0 \mathrm{mg} / \mathrm{kg})$ were administered with each ITI. These doses eliminated responding, and data for those sessions, therefore, are not shown. 


\section{Data Analysis}

During training sessions, responses were separated according to the duration of the stimulus preceding them. Responses that were reinforced after the 2-s stimulus was presented were considered "short" responses and those that were reinforced after the presentation of the 8-s stimulus were considered "long" responses. Proportions approaching 1.0 on long trials indicated that the majority of responses occurred on the long key and proportions approaching 0 on short trials indicated that the majority of responses occurred on the short key. During drug and nondrug test sessions, the mean proportion of long responses were plotted as a function of stimulus duration. A two-parameter logistic function was fitted to these data: $\mathrm{B}=1 /\left(1+\left[d / \mathrm{D}_{50}\right]^{-\varepsilon}\right)$ where $\mathrm{B}$ is the proportion of long responses and $d$ equals the stimulus durations. $\mathrm{D}_{50}$ and $\varepsilon$ are free parameters expressing the point of subjective equality (i.e., the stimulus duration at which the proportion of long responses equals .50) and the slope of the function, respectively.

\section{Results}

Table 2 shows the number of trials necessary to meet the accuracy criterion for the pigeons in each group. Stability was defined as 10 consecutive sessions in which the proportion of long responses on trials in which the stimulus was $8 \mathrm{~s}$ (long) was .80 and the proportion of long responses on trials in which the stimulus was $2 \mathrm{~s}$ (short) was .20. Fewer sessions were necessary for the side-tracking group $(M=5, S D=1)$ to meet this requirement relative to the colortracking group $(M=39, S D=14.71)$.

Figure 3 presents the proportion of long responses as a function of stimulus duration in the absence and presence of $d$-amphetamine for birds in the side-tracking task. The means of the proportion of long responses were calculated and plotted as a function of stimulus duration and 
Table 2

Number of sessions required to meet stability criterion for each group of subjects.

\begin{tabular}{lll}
\hline Task & Pigeon & Sessions \\
& & \\
\hline \multirow{2}{*}{ Side-tracking } & 481 & 4 \\
& 112 & 5 \\
& 393 & 6 \\
& $M$ & 5 \\
Color-tracking & $S D$ & 1 \\
& 128 & 26 \\
& 492 & 55 \\
& 789 & 36 \\
& $M$ & 39 \\
& $S D$ & 14.73 \\
\hline
\end{tabular}


Figure 3 (next page). Proportion of long responses as a function of stimulus duration under drug and non-drug (CON and SAL) conditions for the side-tracking task. The horizontal dashed line indicates the point at which responding occurs equally on the short and long alternatives. The vertical dashed line represents the temporal midpoint (i.e., geometric mean) between 2 and $8 \mathrm{~s}$. Filled circles and solid lines represent proportions for a session with a 10-s ITI and open circles and dashed lines represent proportions for a session with a 100-s ITI. The curves are the best-fit logistic functions (see text). 
SIDE-TRACKING TASK

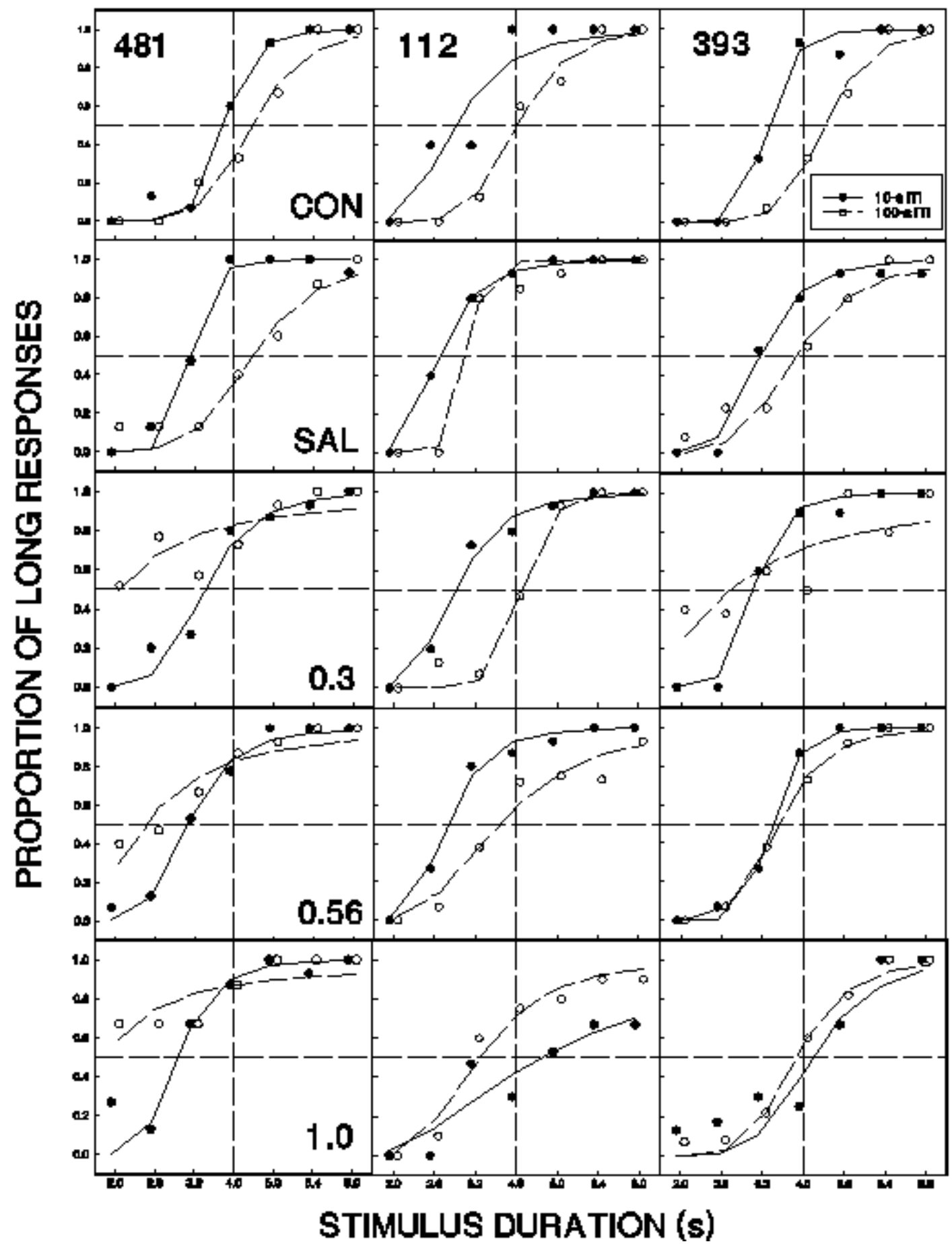


then logistic functions were fitted to the data. Filled circles represent proportions during test sessions with a 10-s ITI and open circles represent proportions during test sessions with a 100-s ITI. Under non-drug conditions (top row), proportion of long responses increased as function of stimulus duration under both ITI conditions for all of the subjects. For all three birds, increasing the ITI produced a rightward shift in the timing functions. Saline (second row) did not alter these functions. $d$-Amphetamine produced inconsistent results. For pigeon 481 (left column), the proportion of long responses was generally unaffected by $d$-amphetamine when the ITI was $10 \mathrm{~s}$. When the ITI was $100 \mathrm{~s}$, however, the timing functions were shifted the left. In addition, as the dose of $d$-amphetamine increased, the functions flattened when the ITI was $100 \mathrm{~s}$. This effect was not as pronounced when the ITI was $10 \mathrm{~s}$. For pigeon 112 (middle column), the 0.3 and $0.56 \mathrm{mg} / \mathrm{kg}$ doses of $d$-amphetamine did not reliably disrupt performance when the ITI was $10 \mathrm{~s}$. When the ITI was $100 \mathrm{~s}$, however, these doses shifted the functions to the right. At the highest dose of $d$-amphetamine (i.e., $1.0 \mathrm{mg} / \mathrm{kg}$ ), responding on the long key decreased under the 10-s ITI condition while the 100-s ITI shifted the function slightly to the left. In addition, the functions at the highest dose of $d$-amphetamine were flatter relative to the other doses and saline. Proportions for pigeon 393 (right column) were generally unaffected by the 0.3 and $0.56 \mathrm{mg} / \mathrm{kg}$ dose of $d$-amphetamine under the shorter ITI condition. When the ITI was $100 \mathrm{~s}$, the 0.3 dose flattened the function while shifting it slightly to the left. The $0.56 \mathrm{mg} / \mathrm{kg}$ dose shifted the $10-\mathrm{s}$ ITI function to the right. Finally, the highest dose of $d$-amphetamine shifted the 10 -s ITI function even further to the right. A substantial flattening of the function was only seen for this pigeon when $0.3 \mathrm{mg} / \mathrm{kg} d$-amphetamine was administered and the ITI was $100 \mathrm{~s}$. In summary, when $d$-amphetamine was absent, the longer ITI shifted the timing functions to the right. Under drug conditions, only one pigeon (481) showed the expected effect. $d$-Amphetamine shifted the 
functions for both ITI conditions to the left, and the shift in the function for the longer ITI condition was much larger. In the other two birds (112 and 393), $d$-amphetamine either produced no effect, shifted the functions to the left, or flattened the functions. Therefore, ITI and $d$-amphetamine produced inconsistent effects for this group of birds.

Figure 4 presents the proportion of long responses as a function of stimulus duration in the absence and presence of $d$-amphetamine for birds in the color-tracking task. Filled circles represent proportions during test sessions with a 10-s ITI and open circles represent proportions during test sessions with a 100-s ITI. When $d$-amphetamine was absent (top two rows), the proportion of long responses increased as a function of stimulus duration for all three birds. No differences were observed between the 10- and 100-s ITI functions for pigeon 128 and 492 (left and middle columns, respectively. For pigeon 789 (right column), the function for sessions with a 100-s ITI was shifted slightly to the right. In general, $d$-amphetamine and ITI had no large or consistent effects on the timing functions. For pigeon 128, $d$-amphetamine shifted both functions slightly to the left. This shift was slightly greater when the ITI was $100 \mathrm{~s}$. No large differences were observed between the 10- and 100-s ITI conditions for this pigeon. For pigeon 492, increasing doses of $d$-amphetamine flattened the functions. Finally, for pigeon 789 , the lowest dose of $d$-amphetamine flattened both functions. The $0.56 \mathrm{mg} / \mathrm{kg}$ dose of $d$-amphetamine did not produce an effect on performance during sessions with a 10-s ITI, but shifted the function for sessions with a 100-s ITI slightly to the left. The highest dose of $d$-amphetamine $(1.0 \mathrm{mg} / \mathrm{kg})$ flattened the function for the longer ITI. In summary, no large or consistent differences were observed when performance under the two different ITI conditions was compared. In addition, $d$-amphetamine generally flattened the functions relating proportion of long responses to stimulus duration, regardless of the ITI conditions. 
Figure 4 (next page). Proportion of long responses as a function of stimulus duration under drug and non-drug (CON and SAL) conditions for the color-tracking task. Other details as in Figure 3. 
COLOR-TRACKING TASK

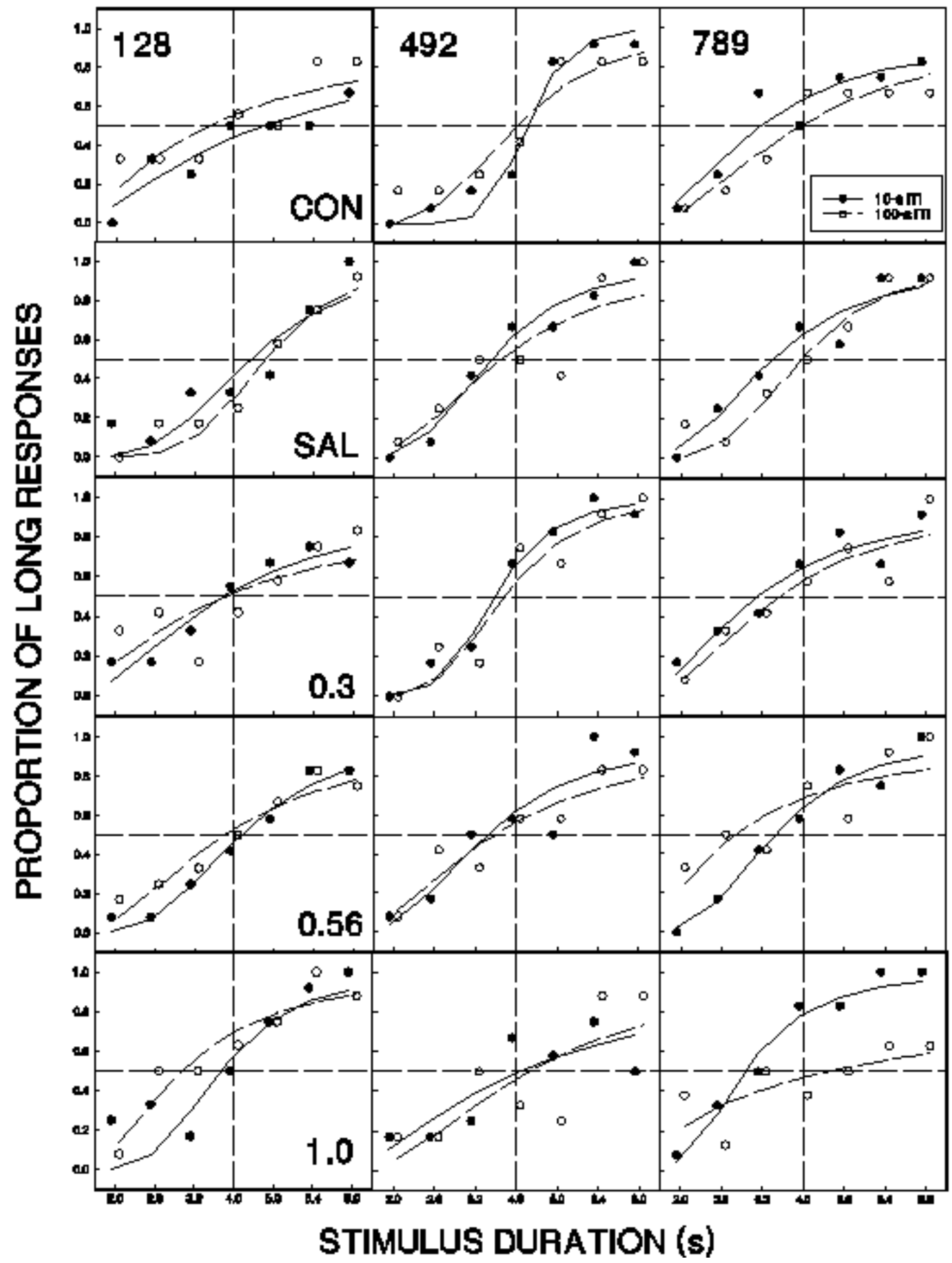


Some notable differences in data for subjects in the side- and color-tracking groups can be observed (Figures 3 and 4). First, under non-drug conditions, the functions for the sidetracking task were placed further left along the abscissa relative to the functions for the colortracking group, indicating that pigeons in the side-tracking task responded on the long key at short durations that produced responding on the short key in the color-tracking group. When the ITI was increased, the timing functions for the side-tracking group shifted to the right. Conversely, increasing the ITI during the color-tracking task had no large effect on performance, with the exception of a slight rightward shift for pigeon 789. In the side-tracking group, $d$ amphetamine shifted the functions to the left, to the right, or not at all. In addition, increasing the ITI and administering the higher doses of $d$-amphetamine flattened the curves. For the colortracking group, on the other hand, very few differences between the long and short ITI conditions were observed when $d$-amphetamine was administered. In general, increasing doses of $d$-amphetamine flattened the functions for this group.

The means and standard deviations of the free parameters from the curves used to generate the functions in Figures 3 and 4 are shown in Tables 3 and 4 for the side- and colortracking groups, respectively. Both the slope and the time at which 50\% of responding occurred were generated. Decreases in the slope, or $\varepsilon$, indicate a flattening of the functions while higher slopes indicate a steeper function. Decreases in $\mathrm{D}_{50}$ indicate a shift in the left of the function while increases in $\mathrm{D}_{50}$ indicate a rightward shift of the function. The data in Tables 3 and 4 are consistent with those represented in Figure 3 and 4. First, the $\mathrm{D}_{50}$ 's for the side-tracking task were lower under saline conditions compared to the color-tracking task. In addition, increasing the ITI increased the $\mathrm{D}_{50}$ for the side-tracking group while the $\mathrm{D}_{50}$ was unaffected by the ITI for the color-tracking group. Second, the slopes of the functions were generally higher for 
Table 3

Means and standard deviations of the parameters of logistic functions fitted to the data from individual pigeons for the side-tracking group.

\begin{tabular}{|c|c|c|c|c|c|c|}
\hline Parameters & ITI & Control & Saline & $0.3 \mathrm{mg} / \mathrm{kg}$ & $0.56 \mathrm{mg} / \mathrm{kg}$ & $1.0 \mathrm{mg} / \mathrm{kg}$ \\
\hline Pigeon 481 & $10 \mathrm{~s}$ & & & & & \\
\hline Slope, $\varepsilon$ & & $10.82(5.26)$ & $34.2(1.54)$ & $12.73(8.97)$ & $19.97(13.26)$ & $15.23(16.94)$ \\
\hline $\mathrm{D}_{50}(\mathrm{~s})$ & & $3.87 \quad(.63)$ & $3.1 \quad(.4)$ & $3.52(.72)$ & $3.37 \quad(.74)$ & $2.68(1.04)$ \\
\hline $\mathrm{R}^{2}$ & & $.99 \quad(.01)$ & $.98 \quad(.01)$ & $.96 \quad(0.2)$ & $.99 \quad(.01)$ & $.9 \quad(.03)$ \\
\hline $\begin{array}{l}\text { Slope, } \varepsilon \\
\mathrm{D}_{50}(\mathrm{~s}) \\
\mathrm{R}^{2}\end{array}$ & $100 \mathrm{~s}$ & $\begin{array}{ll}6.45 & (1.56) \\
4.38 & (.87) \\
.97 & (.02)\end{array}$ & $\begin{array}{ll}7.92 & (.18) \\
4.5 & (.94) \\
.95 & (.03)\end{array}$ & $\begin{array}{ll}2.36 & (1.44) \\
2.32 & (1.71) \\
.63 & (.12)\end{array}$ & $\begin{array}{ll}6.46 & (1.03) \\
2.52 & (.49) \\
.88 & (.05)\end{array}$ & $\begin{array}{l}2.83 \\
1.94 \\
.62\end{array}$ \\
\hline $\begin{array}{l}\text { Pigeon } 112 \\
\text { Slope, } \varepsilon \\
D_{50}(s) \\
R^{2}\end{array}$ & $10 \mathrm{~s}$ & $\begin{array}{ll}8.63 & (17.24) \\
3.06 & (.25) \\
.92 & (.03)\end{array}$ & $\begin{array}{ll}23.84 & (16.04) \\
2.81 & (.3) \\
1.0 & (0)\end{array}$ & $\begin{array}{ll}17.67 & (18.84) \\
2.89 & (.43) \\
.99 & (.02)\end{array}$ & $\begin{array}{ll}18.63 & (17.17) \\
3.13 & (.19) \\
.99 & (.02)\end{array}$ & $\begin{array}{ll}5.36 & (.12) \\
4.55 & (.23) \\
.85 & (.11)\end{array}$ \\
\hline $\begin{array}{l}\text { Slope, } \varepsilon \\
\mathrm{D}_{50}(\mathrm{~s}) \\
\mathrm{R}^{2}\end{array}$ & $100 \mathrm{~s}$ & $\begin{array}{ll}6.98 & (3.68) \\
3.98 & (.76) \\
.98 & (.01)\end{array}$ & $\begin{array}{ll}22.57 & (25.5) \\
3.27 & (.36) \\
.98 & (.01)\end{array}$ & $\begin{array}{cl}22.2 & (15.8) \\
4.11 & (.98) \\
.99 & (.004)\end{array}$ & $\begin{array}{ll}6.32 & (3.32) \\
3.83 & (1.5) \\
.96 & (.02)\end{array}$ & $\begin{array}{ll}6.21 & (3.92) \\
3.2 & (.23) \\
.97 & (.02)\end{array}$ \\
\hline
\end{tabular}


Table 3 (cont.)

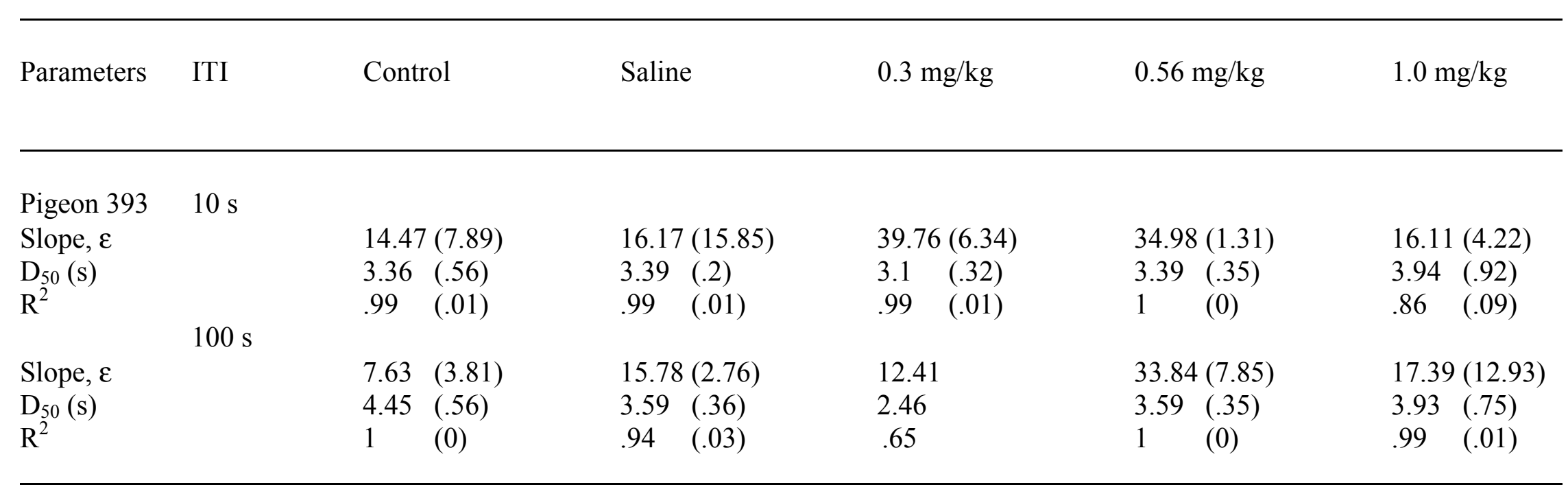


Table 4

Means and standard deviations of the parameters of logistic functions fitted to the data from individual pigeons for the color-tracking group.

$\begin{array}{llllll}\text { Parameters } & \text { ITI } & \text { Control } & \text { Saline } & 0.3 \mathrm{mg} / \mathrm{kg} & 0.56 \mathrm{mg} / \mathrm{kg}\end{array}$

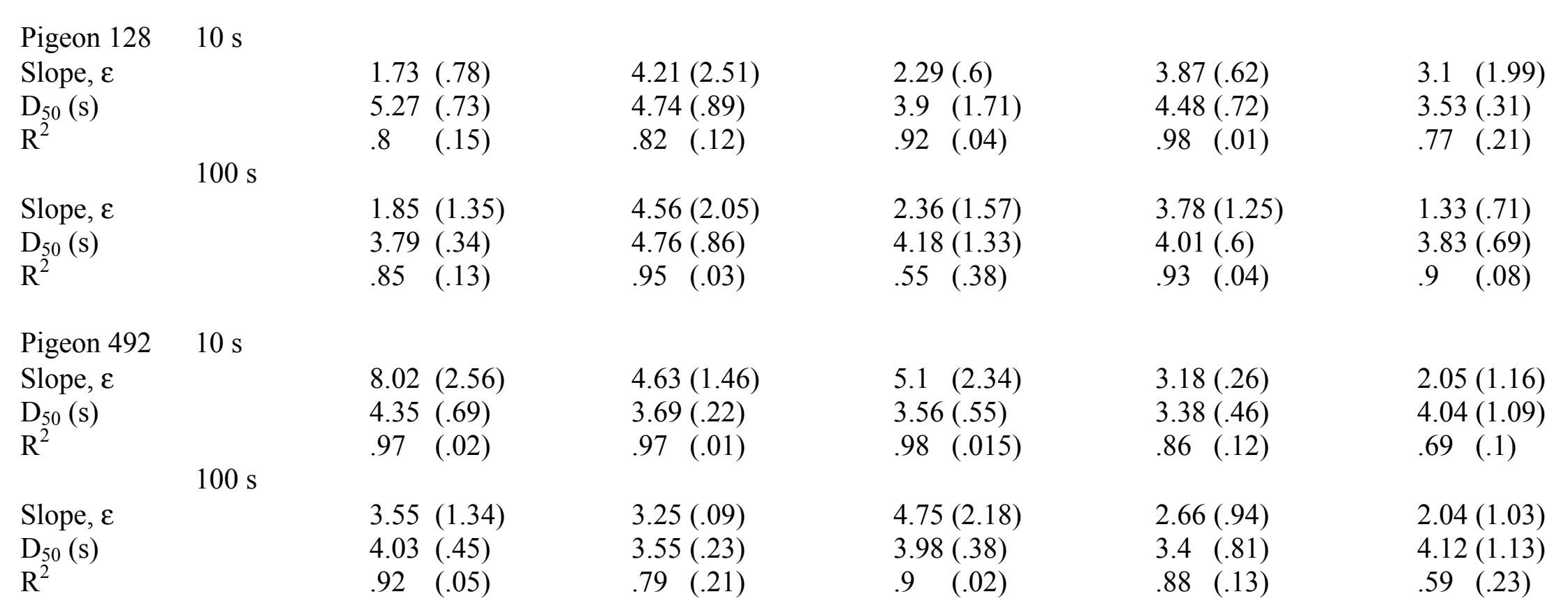


Table 4 (cont.)

\begin{tabular}{|c|c|c|c|c|c|c|}
\hline Parameters & ITI & Control & Saline & $0.3 \mathrm{mg} / \mathrm{kg}$ & $0.56 \mathrm{mg} / \mathrm{kg}$ & $1.0 \mathrm{mg} / \mathrm{kg}$ \\
\hline Pigeon 789 & $10 \mathrm{~s}$ & & & & & \\
\hline Slope, $\varepsilon$ & & $2.47(1.86)$ & $4.04(2.31)$ & $3.45(2.43)$ & $5.3 \quad(3.17)$ & $3.36(1.67)$ \\
\hline $\mathrm{D}_{50}(\mathrm{~s})$ & & $3.53(.57)$ & $3.56(.46)$ & $3.28(.6)$ & $3.46(.51)$ & $3.02(.56)$ \\
\hline $\mathrm{R}^{2}$ & & $.82 \quad(.15)$ & $.94 \quad(.03)$ & $.9 \quad(.08)$ & $.97 \quad(.04)$ & $.97 \quad(.023)$ \\
\hline & $100 \mathrm{~s}$ & & & & & \\
\hline Slope, $\varepsilon$ & & $2.23(.67)$ & $3.51(.5)$ & $2.43(.66)$ & $4.78(5.79)$ & $1.8 \quad(1.45)$ \\
\hline $\mathrm{D}_{50}(\mathrm{~s})$ & & $4.18(.43)$ & $4.18(.31)$ & $4.03(1.22)$ & $2.62(.52)$ & $4.23(.88)$ \\
\hline $\mathrm{R}^{2}$ & & $.81 \quad(.16)$ & $.94 \quad(.05)$ & $.86(.13)$ & $.7 \quad(.24)$ & $.51 \quad(.33)$ \\
\hline
\end{tabular}


performance maintained by the side-tracking task relative to the color-tracking task.

Figure 5 shows the mean latency to peck the center key at the beginning of trials for both ITI conditions as a function of dose of $d$-amphetamine for the side-tracking group. Under control conditions, the latencies were either the same or slightly higher for the longer ITI condition for all birds. Saline did slightly decrease the mean latencies for both ITI conditions for pigeon 112. Saline increased the latencies for pigeon 481 and 393 when the ITI was $100 \mathrm{~s}$ and slightly decreased the latency for pigeon 393 when the ITI was $10 \mathrm{~s} . d$-Amphetamine increased the latencies when the ITI was $100 \mathrm{~s}$ for pigeon 481 and 393. The mean latencies under the 10-s ITI condition were either unaffected or increased slightly at the highest dose of $d$-amphetamine (pigeons 112 and 393).

Figure 6 shows the mean latency to peck the center key at the beginning of trials for both ITI conditions as a function of dose of $d$-amphetamine for the color-tracking group. Under control conditions, increasing the ITI increased the latency to peck the center key for all of the pigeons. Saline decreased the latencies for pigeon 128 when the ITI was $100 \mathrm{~s}$. Saline did not affect the other latencies. For pigeon 128, $d$-amphetamine decreased the latencies when the ITI was $100 \mathrm{~s}$ relative to control conditions. The highest dose of $d$-amphetamine $(1.0 \mathrm{mg} / \mathrm{kg})$ slightly decreased the latencies for the 100-s ITI condition for pigeon 492. In addition, the highest dose of $d$-amphetamine increased the latencies for the 100-s ITI condition for pigeon 789. In general, therefore, increasing the ITI increased the mean latency to peck the center key at the beginning of the trial for both groups. Only the highest dose of $d$-amphetamine affected the latencies. 
Figure 5 (next page). Effects of $d$-amphetamine on the mean latency (s) to peck the center key at the beginning of trials for the side-tracking task. Filled circles indicate latencies for sessions with a 10-s ITI and open circles represent latencies for sessions with a 100-s ITI. Unconnected points show mean latencies for all control sessions (C) and determinations of saline (S). Lines connect points showing mean latencies for at least two determinations of each dose. Vertical bars represent one standard deviation above and below means. 


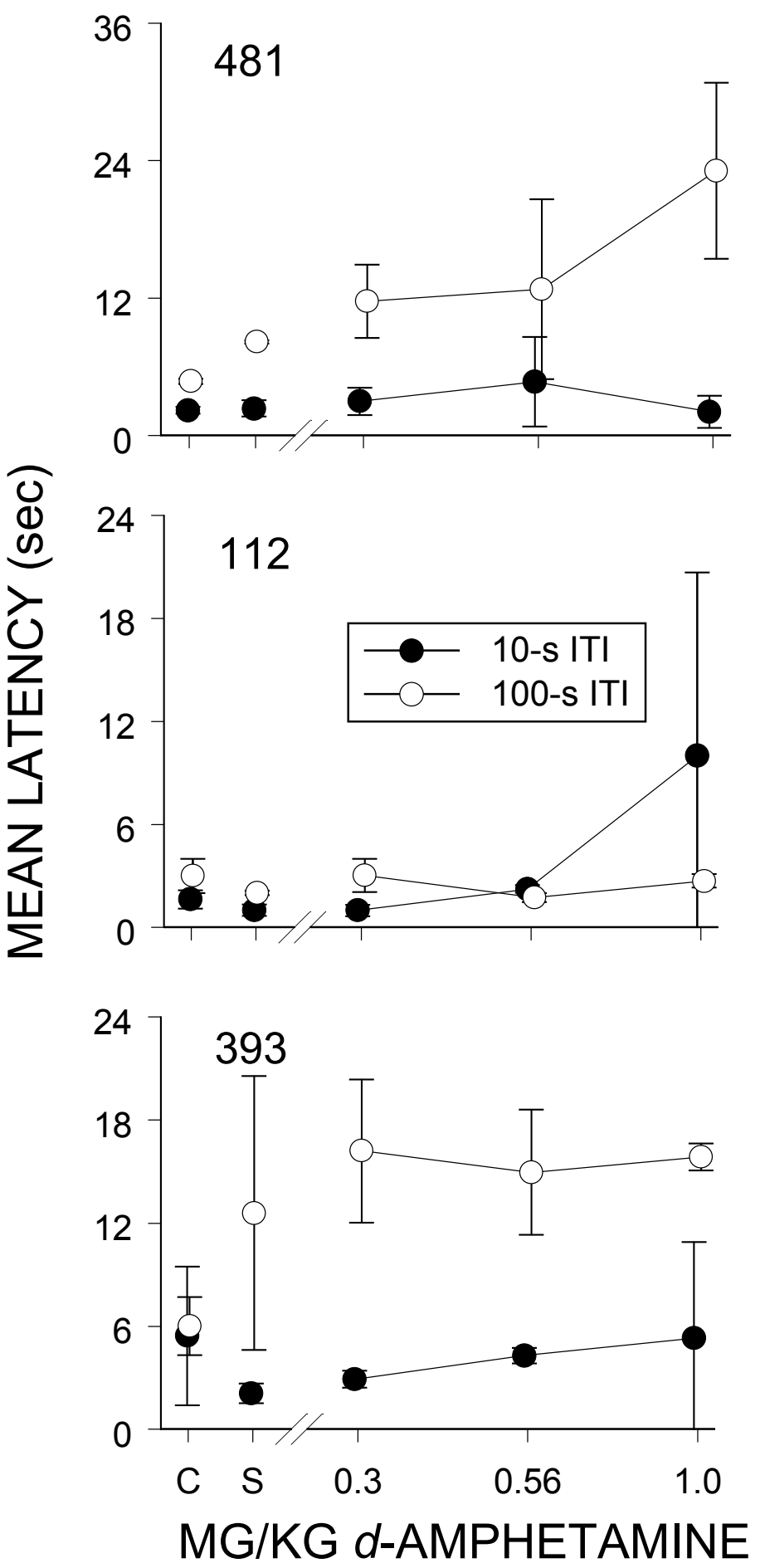


Figure 6 (next page). Effects of $d$-amphetamine on the mean latency (s) to peck the center key at the beginning of trials for the color-tracking task. Other details as in Figure 5. 

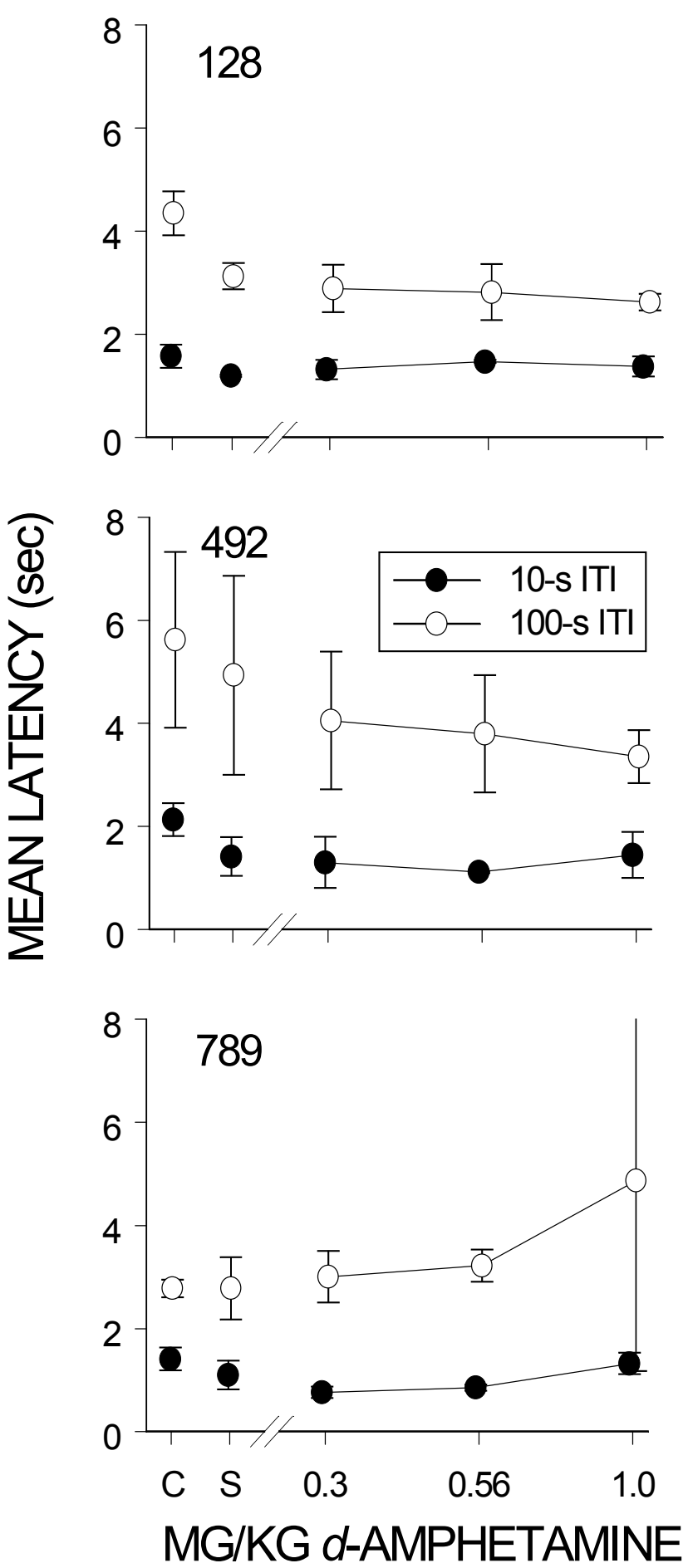


\section{Discussion}

The effects of the ITI and $d$-amphetamine on performance maintained by both the side and color-tracking tasks first will be summarized and compared. Then the results of the present experiment will be compared to the results of previous research. Finally, alternative explanations for the findings of the present experiment will be offered.

\section{Summary and Comparison of Results}

Under non-drug conditions, functions relating the proportion of long key responses to stimulus duration were shifted to the left in the side-tracking group relative to the color-tracking group when the ITI was $10 \mathrm{~s}$ (see Figures 3 and 4). That is, the pigeons were more likely to peck the long key at shorter stimulus durations. This effect is likely related to the behavior that occurred during the presentation of the temporal stimulus. Based on observations of the pigeons during sessions, it was determined that, during the side-tracking task, clear behavioral patterns occurred. The pigeons stood in front of the left key (the key pecks to which were reinforced after the 2-s stimulus) and then moved over to the right key (the key pecks to which were reinforced after the 8-s stimulus). When the intermediate stimulus durations were introduced during test sessions, this behavioral pattern persisted. Therefore, when stimulus durations were longer than $2 \mathrm{~s}$, in many cases the pigeons in the side-tracking group had already moved to the right key. A behavioral pattern like this did not occur in the color-tracking group. A more comprehensive and detailed analysis of these behavioral patterns based on videotapes was considered, but given the lack of consistent effects, was not completed.

These results are consistent with other experiments examining collateral behavior during an interval bisection task. For example, Fetterman, Killeen, and Hall (1998) measured the collateral behaviors of four pigeons responding on an interval bisection task. Two of the pigeons 
responded on a task similar to the side-tracking task in the present experiment. Pecking or bobbing in front of both keys were measured, as well as moving from one key to the other. At the beginning of the trials, both birds in the side-tracking group either bobbed or pecked in front of the key associated with the short stimulus. As the time throughout the trial increased, these behaviors were gradually replaced with either pecking or bobbing in front of the key associated with the long stimulus. These findings are consistent with observations of the pigeons in the present experiment. Two other birds were trained on a task similar to the color-tracking task in the present experiment. Collateral behaviors did develop (i.e., head bobbing in the corner and pecking the houselight) and if a short stimulus was presented, a small number of collateral responses occurred before a response. Similarly, if the long stimulus was presented, a larger number of collateral responses occurred before a response. The collateral responses were not related to accuracy, however, because the same number of responses occurred on a short (or long) trial irrespective of whether a correct or incorrect response was made.

Given the relation between collateral responses and accuracy in the side-tracking task, it is clear that the side-tracking task sets the occasion for considerably different behavior relative to the color-tracking task. In the side-tracking task, the pigeons can stand in front of the short key and then, after approximately $2 \mathrm{~s}$, move to the long key. It is suggested that discrimination in the side-tracking group was based on whether or not $2 \mathrm{~s}$ had passed. Once $2 \mathrm{~s}$ elapsed, they moved to the other key and may not have even attended to the last $6 \mathrm{~s}$ of the stimulus. In the colortracking task, on the other hand, the pigeons had to wait until the time of the stimulus presentation elapsed before moving toward the correct key, thereby attending to both stimulus durations in their entirety. Therefore, one could argue that the side-tracking task is easier relative to the color-tracking task because the discrimination in the side-tracking task was based 
on behavior that was governed by whether or not $2 \mathrm{~s}$ had elapsed rather than based on a comparison of 2 and $8 \mathrm{~s}$ that was required in the color-tracking task. The number of sessions necessary to reach the accuracy criterion is consistent with this notion (see Table 2) because it took fewer sessions to learn the discrimination in the side-tracking group relative to the colortracking group.

In the present experiment, the pigeons were required to peck the center key to start the trial. One reason for this was to ensure that the pigeons were centered between the side keys at the onset of the trial. Including this in the procedure was ineffective in decreasing the likelihood that the pigeons would move from the left to the right key during the trial in the side-tracking task. This is consistent with the findings of an experiment conducted by Chiang et al (2000). Rats were trained to respond on the interval bisection task similar to the side-tracking task in the present experiment and then were divided into two groups: the "poke-requirement" and "nopoke-requirement" groups. In both groups, the houselight was lit and after either 2 or $8 \mathrm{~s}$ elapsed, the houselight was extinguished. In the "no-poke-requirement" procedure, two levers then were inserted into chambers. In the "poke-requirement" procedure, the levers were not inserted into the chamber until the rats had poked their noses into a hole in the center of the instrumental panel. Intermediate stimulus durations were then tested. No significant differences were observed in the timing functions of the two groups. Therefore, the poke-requirement did not alter performance. It may be the case, however, that in both the Chiang et al (2000) experiment and the present experiment, the responses that were required to either initiate the trial or the presence of the response levers did not completely constrain moving from the left to the right during the trial. The subjects in the present experiment could have simply pecked the center key and moved to the left key. Similarly, in the Chiang et al (2000) study, the rats could 
have stood in front of the lever and moved to the right lever later in the trial. After the nose-poke response occurred, the rats could have moved back to where they were located before the houselight extinguished.

Another interesting finding of the present experiment is that under non-drug conditions, increasing the ITI in the side-tracking task shifted the timing functions to the right. This finding was in contrast to the expected effect of the ITI and did not occur in the color-tracking group. It was proposed that by increasing the ITI, the value of the temporal stimulus would also be increased, which would be reflected in a leftward shift of the function. In the present experiment, however, the functions shifted to the right when the ITI was increased. Based on an interpretation of stimulus value, this finding might suggest that increasing the ITI decreased rather than increased the stimulus value. In addition, it was expected that by increasing the ITI, the latency to peck the center key to initiate the trial would decrease. The latencies to peck the center key, however, increased when the ITI was increased. These two findings, that increasing the ITI increased latencies to initiate the trial and produced a rightward shift in the functions, are therefore consistent with the notion that stimulus value was decreased when the ITI was increased. It is important to remember, however, that increasing the ITI in the color-tracking task also produced an increase in the latency to initiate the trial, but did not produce shifts in the functions relating proportion of long responses to stimulus duration. One possible explanation for the increased latencies is related to the specific ITI conditions. During the ITI, all of the lights in the chamber were extinguished. Therefore, the pigeons were sitting in a completely darkened chamber for $100 \mathrm{~s}$. The increased latencies may simply reflect the time it took for the pigeons to move around the chamber after sitting in the dark for a relatively long time. Thus, the present experiment may not have provided the best test of the effects of ITI given that the lights 
were out during the entire ITI. It may be the case that different results would be obtained if the ITI was lit rather than dark.

Finally, the present experiment produced inconsistent results with respect to the effects of $d$-amphetamine on performance maintained by the interval bisection task. In many cases, $d$ amphetamine either did not affect or shifted the functions to the right relative to non-drug conditions. Procedural differences may account for the difference in the findings of the present experiment and those of previous studies. First, the range of doses tested in the present experiment may have been too restricted to produce the effect. In most cases, $d$-amphetamine did not produce large effects on responding until the highest dose was administered (see Figures 3 and 4). It may be that if higher doses had been administered, $d$-amphetamine would have produced larger effects that were consistent with previous research. Higher doses (1.7 and 3.0 $\mathrm{mg} / \mathrm{kg}$ ), however, were administered in the present experiment, but completely eliminated responding in all of the pigeons. In addition, the doses that were tested were comparable to those used previously in experiments that produced a leftward shift in functions (e.g., Kraemer, Randall, Dose \& Brown, 1997). Therefore, it seems as though the range of doses used in the present experiment was appropriate for testing the effects of $d$-amphetamine on performance maintained by an interval bisection task.

One other variable may account for the differences in the effects of $d$-amphetamine on temporally organized in the present experiment relative to previous findings. In previous studies, the testing of drugs began relatively shortly after responding on the interval bisection task was acquired. Drug testing began after a minimum of 12 (Maricq, Roberts, \& Church, 1981), 18 (Meck, 1983), 35 (Maricq \& Church, 1983) or 60 (Bizot, 1997) sessions of training. In the present experiment, however, the subjects experienced a minimum of 65 sessions to a maximum 
of 84 sessions prior to drug testing in the side-tracking group and a minimum of 119 to a maximum of 171 training sessions prior to drug testing in the color-tracking group. In addition, drug testing in previous experiments was completed in fewer sessions. More specifically, drug testing was completed over the course of 4 (Meck, 1983), 18 (Bizot, 1997), 25 (Maricq \& Church, 1983), or 50 (Maricq, Roberts, \& Church, 1981) sessions. In the present experiment, however, drug testing required an average of 153 sessions for the side-tracking task and 272 sessions for the color-tracking task. The difference in exposure to baseline conditions is primarily a function of the fact that many of the studies either tested only one dose of the drug or tested multiple doses of a drug only once, whereas in the present experiment, several doses were tested under two different ITI conditions and multiple determinations were completed. In addition, baseline performance in the color-tracking task was often not stable enough to conduct testing every fourth day. Therefore, the present experiment differed in the exposure to baseline conditions relative to previous studies that have assessed the effects of drugs on performance maintained by an interval bisection task. It may be the case that increased exposure to baseline conditions produced behavior that was more resistant to the effects of $d$-amphetamine. This may also explain why performance in the color-tracking task was relatively unaffected by both the ITI and $d$-amphetamine because subjects in this group experienced almost twice as many sessions relative to the side-tracking group. It is possible that increased exposure to baseline conditions may increase stimulus control. It has been shown that behavior maintained under stronger stimulus control is less likely to be affected by drugs than behavior maintained by weaker stimulus control (e.g., Katz, 1983). A test of this explanation would simply require one to vary the exposure to baseline conditions prior to drug testing. The results of an experiment like this 
may clarify the discrepancies between the findings of the present experiment and previous findings.

In summary, the present experiment produced results that were inconsistent with the expectations based on previous findings. First, increasing the ITI did not produce consistent leftward shifts in the functions relating the proportion of long responses to stimulus duration. Rather, increasing the ITI either had no effect or shifted the functions to the right. Second, $d$ amphetamine also did not produce consistent leftward shifts in the functions relating the proportion of long responses to stimulus duration in either group of pigeons. Finally, increasing the ITI and administering $d$-amphetamine only produced an additive effect in one of six pigeons. Several explanations based on procedural variations have been offered to account for the differences in the findings of the present experiment and those of other experiments. The inconsistencies between previous and present experiments may, however, simply reflect more general inconsistencies in the effects of ITI on temporally organized behavior and the effects of psychomotor stimulants on both responding maintained by conditioned reinforcement and temporally organized behavior. The remainder of this discussion will review these areas of research and relate the findings of previous research to the present findings.

\section{Inconsistencies in Research}

\section{Effects of ITI on temporally organized behavior.}

Several studies have reported that increasing the ITI shifts timing functions to the left (Raslear, Shurtleff, \& Simmons, 1992; Santi, Coyle, Coppa, \& Ross, 1998). In the present experiment, however, increasing the ITI had the opposite effect. A number of studies have found that increasing the ITI either had no effect on temporally organized behavior (Church, Miller, Meck, \& Gibbon, 1991; Spetch \& Rusack, 1992) or produced rightward shifts in the timing 
functions (Bizo \& White, 1994; Killeen \& Fetterman, 1988). For example, Bizo and White (1994) trained pigeons to respond on a free-operant psychophysical procedure. At the onset of a 50-s trial, the side keys in the chamber were both lit orange. During the first $25 \mathrm{~s}$ of the trial, responding on the left key was reinforced on a variable-interval 30-s (VI 30 s) schedule of food reinforcement. Pecking the right key during the first $25 \mathrm{~s}$ was not reinforced. During the second $25 \mathrm{~s}$ of the trial, the conditions were reversed: pecking the right key produced reinforcement on a VI 30-s schedule while responding on the left key did not produce reinforcement. No stimulus changes occurred throughout the trial to signal the availability of reinforcement on the right key. Right-key responses within consecutive 5-s segments of the trial were divided by total pecks during the 5-s segments and plotted as a function of time in trial to produce timing functions similarly to those produced in the present experiment. At the beginning of the trial, proportion of right key pecks was 0 and increased as a function of time throughout the interval. Training began with a 10-s ITI and alternated with conditions in which the ITI was either 70 or $190 \mathrm{~s}$. When the ITI was increased, the function relating proportion of right-key pecks shifted to the right. Similarly, Killeen \& Fetterman (1988) described unpublished findings from their laboratory that were consistent with the current findings. Half of the subjects were trained with a 15-s ITI while the other half were trained with a 180 -s ITI. When the ITI conditions were reversed (i.e., $15 \mathrm{~s}$ to $180 \mathrm{~s}$ and $180 \mathrm{~s}$ to $15 \mathrm{~s}$ ) increasing the ITI shifted the timing functions to the right while decreasing the ITI shifted the timing functions to the left. The discrimination of the temporal stimuli, therefore, was affected in a manner that was inconsistent with predictions based on the value of the stimuli. Even though increasing the ITI should increase the value of the temporal stimuli, it also decreased the rate of reinforcement. As discussed above, increases in the rate of reinforcement produced leftward shifts in timing functions (Morgan, Killeen, and 
Fetterman, 1993). Based on those findings, decreases in the rate of reinforcement should produce the opposite effect. These findings are similar to the results of the present experiment. Therefore, the rightward shifts observed in the side-tracking condition in the present experiment may be a function of decreases in the rate of reinforcement, rather than any changes in stimulus value.

\section{Effects of psychomotor stimulants on responding maintained by conditioned} reinforcement.

Several experiments have shown that psychomotor stimulants enhance the conditionedreinforcing effects of stimuli associated with reinforcement (Mazurski \& Beninger, 1986; Robbins, 1978; Robbins, Watson, Gaskin, \& Ennis, 1983; Wolterink et al, 1993). Robbins (1978), however, was not able to produce this effect with $d$-amphetamine. Water-deprived rats were trained to place their heads through a flap to drink water. The availability of water was preceded by 0.5 -s light flash. After the rats reliably placed their heads through the flap, the delivery of water no longer occurred. Rather, pressing one of two levers would produce the light flash that had been previously associated with water delivery. Several different psychomotor stimulants, including $d$-amphetamine, then were administered. Both pipradrol and methylphenidate increased responding on the lever the produced the conditioned reinforcer (the light flash) while either decreasing or not effecting responding on the lever that had no consequences. $d$-Amphetamine did not increase responding on the lever associated with the delivery of conditioned reinforcement. Hill (1972; as cited in Robbins, 1978) also found that pipradrol was more effective in increasing responding associated with conditioned reinforcement relative to $d$-amphetamine. Both authors suggested that the inconsistent effects of $d$ amphetamine relative to other psychomotor stimulants may reflect slightly different 
pharmacological actions of the drugs. Given the inconsistent effects of $d$-amphetamine on stimulus value, it may be that $d$-amphetamine did not alter the stimulus value in the present experiment. Therefore, it may be worthwhile to examine the effects of other psychomotor stimulants, such as pipradrol, on behavior maintained on the procedure used in the present experiment.

\section{Effects of psychomotor stimulants on temporally organized behavior.}

In the present experiment, $d$-amphetamine did not reliably produce leftward shifts in the timing functions in either the side- or color-tracking groups. This finding is in contrast to several other studies (Bizot, 1997, Kraemer, Randall, Dose \& Brown, 1997; Maricq, Roberts, \& Church, 1981; Maricq \& Church, 1983; Meck, 1983). These studies used a variety of psychomotor stimulants and methods to arrange temporally organized behavior and reliably produced leftward shifts in timing functions. Other studies, however, have produced either inconsistent effects (Rapp \& Robbins, 1976; Santi, Weise, \& Kuiper, 1995; Stubbs \& Thomas, 1974) or showed that psychomotor stimulants flattened timing functions (Chiang et al, 2000; Shurtleff, Raslear, Genovese, \& Simmons, 1992; Stanford \& Santi, 1998). Although it is clear that the effects of psychomotor stimulants on temporally organized behavior are inconsistent, the reasons for those inconsistencies are not clear. When comparing the procedural variables that may affect the outcome of the experiments, there is considerable overlap between studies in which $d$ amphetamine produced an overestimation of time and those that did not. Even if the review is limited to studies using the interval bisection task, there is considerable variability across procedures. While some studies used the side-tracking task (e.g., Chiang et al, 2000; Maricq \& Church, 1983), others used the color-tracking task (e.g., Stubbs \& Thomas, 1974). Several studies used correction procedures during training (Chiang et al, 2000; Maricq \& Church, 1983; 
Shurtleff, Raslear, Genovese, \& Simmons, 1992; Stanford \& Santi, 1998), while others did not (Maricq, Roberts, \& Church, 1981; Meck, 1983; Stubbs \& Thomas, 1974). In addition, some studies tested only one dose of the drug (Maricq \& Church, 1983; Maricq, Roberts, \& Church, 1981; Meck, 1983; Santi, Weise, \& Kuiper, 1995; Stanford \& Santi, 1998), tested a range of doses multiple times (the present experiment; Chiang et al, 2000; Shurtleff, Raslear, Genovese, \& Simmons, 1992), or tested a range of doses once (Rapp \& Robbins, 1976; Stubbs \& Thomas, 1974). Therefore, it is unclear whether $d$-amphetamine did not produce an effect in the present experiment because it failed to alter the stimulus value or because of a procedural variable that was either modified or not present. Clearly, it is important to determine the specific variables that are necessary to produce either consistent shifts in timing functions or consistent flattening of those functions. 


\section{References}

Bizo, L. A., \& White, K. G (1994). Pacemaker rate in the behavioral theory of timing. Journal of Experimental Psychology: Animal Behavior Processes, 20 (3), 308 - 321.

Bizot, J. C. (1997). Effects of psychoactive drugs on temporal discrimination in rats. Behavioural Pharmacology, 8, 293-308.

Brown, P. L., \& Jenkins, H. M. (1968). Autoshaping of the pigeon's key-peck. Journal of the Experimental Analysis of Behavior, 11, 1-8.

Chiang, T. J., Al Ruwaitea, A. S. A., Mobini, S., Ho, M. Y., Bradshaw, C. M., \& Szabadi, E. (2000). The effects of $d$-amphetamine on performance on two operant timing schedules. Psychopharmacology, 150, 170-184.

Church, R. M., \& Deluty, M. (1977). Bisection of temporal intervals. Journal of Experimental Psychology: Animal Behavior Processes, 3, 216 - 228.

Church, R. M., Miller, K. D., Meck, W. H., \& Gibbon, J (1991). Symmetrical and asymmetrical sources of variance in temporal generalization. Animal Learning and Behavior, 19 (3), $207-214$.

Fetterman, J. G., Killen, P. R., \& Hall, S. (1998). Watching the clock. Behavioural Processes, 44, $211-224$.

Gibbon, J., Locurto, C, \& Terrace, H. S. (1975). Signal-food contingency and signal frequency in a continuous trials auto-shaping paradigm. Animal Learning \& Behavior, 3, 317 324.

Hill, R. T. (1972). Animal models of the euphorigenic action of amphetamine-like psychomotor stimulant drugs. Paper presented at the annual meeting of the American Psychological Association (Div. 28), Honolulu, Hawaii. 
Holder, M. D., \& Roberts, S. (1985). Comparison of timing and classical conditioning. Journal of Experimental Psychology: Animal Behavior Processes, 1, 172 - 193.

Kaplan, P. S. (1984). Importance of relative temporal parameters in trace conditioning: From excitation to inhibition. Journal of Experimental Psychology: Animal Behavior Processes, $10,113-126$.

Katz, J. L. (1983). Effects of drugs on stimulus control of behavior. II: Degree of stimulus control as a determinant of effect. Journal of Pharmacology and Experimental Therapeutics, 226, $308-321$.

Killeen, P. R., \& Fetterman, J. G. (1988). A behavioral theory of timing. Psychological Review, 95 (2), $274-295$.

Kirkpatrick, K, \& Church, R. M. (1998). Are separate theories of conditioning and timing necessary? Behavioural Processes, 44, 163 - 182.

Kraemer, P. J., Randall, C. K., Dose, J. M., \& Brown, R. W. (1997). Impact of $d$ amphetamine on temporal estimation in pigeons tested with a production procedure. Pharmacology, Biochemistry, \& Behavior, 58, 323 - 327.

Maricq, A. V., \& Church R. M. (1983). The differential effects of haloperodil and methamphetamine on time estimation in the rat. Psychopharmacology, 79, $10-15$.

Maricq, A. V., Roberts, S., \& Church, R. M. (1981). Methamphetamine and time estimation. Journal of Experimental Psychology: Animal Behavior Processes, 7, 18 - 30.

Mazurski, E. J., \& Beninger, R. J. (1986). The effects of (+)-amphetamine and apomorphine on responding for a conditioned reinforcer. Psychopharmacology, 90, 239 - 243.

Meck, W. H. (1983). Selective adjustment of the speed of internal clock and memory processes. Journal of Experimental Psychology: Animal Behavior Processes, 9, 171 - 201. 
Morgan, L., Killeen, P. R., \& Fetterman, J. G. (1993). Changing rates of reinforcement perturbs the flow of time. Behavioural Processes, 30, 259-272.

Nevin, J. A., Mandell, C., \& Atak, J. R. (1983). The analysis of behavioral momentum. Journal of the Experimental Analysis of Behavior, 39, 49 - 59.

Oberdieck, F., Cheney, C. D., \& Mueller, D. L (1978). An examination of autoshaped keypecking in a dark chamber. Psychological Reports, 43, $1299-1312$.

Rapp, D. L., \& Robbins, T. W. (1976). The effects of $d$-amphetamine on temporal discrimination in the rat. Psychopharmacology, 51, $91-100$.

Raslear, T. G., Shurtleff, D., \& Simmons, L. (1992). Intertrial-interval effects in sensitivity (A') and response bias (B") in a temporal discrimination by rats. Journal of the Experimental Analysis of Behavior, 58, 527 - 535.

Rescorla, R. A. (1968). Probability of shock in the presence and absence of CS in fear conditioning. Journal of Comparative and Physiological Psychology, 66, 1-5.

Robbins, T. W. (1978). The acquisition of responding with conditioned reinforcement: Effects of pipradrol, methylphenidate, $d$-amphetamine and nomifensine. Psychopharmacology, $58,79-87$.

Robbins, T. W., Watson, B.A, Gaskin, M., \& Ennis, C. (1983). Contrasting interactions of pipradrol, $d$-amphetamine, cocaine, cocaine analogues, apomorphine and other drugs with conditioned reinforcement. Psychopharmacology, 80, $113-119$.

Roberts, S. \& Holder, M. D. (1985). Effect of classical conditioning on an internal clock. Journal of Experimental Psychology: Animal Behavior Processes, 11, $194-214$. 
Santi, A., Coyle, J., Coppa, R., \& Ross, L. (1998). The timing of auditory and visual signals by pigeons: Differential sensitivity to intertrial interval duration. Learning and Motivation, 29, $345-365$.

Santi, A., Weise, L., Kuper, D. (1995). Amphetamine and memory for event duration in rats and pigeons: Disruption of attention to temporal samples rather than changes in the speed of the internal clock. Psychobiology, 203 (3), $224-232$.

Shurtleff, D., Raslear, T. G., Genovese, R. F., \& Simmons, L. (1992). Perceptual bisection in rats: The effects of physostigmine, scopolamine, and pirenzepine. Physiology and Behavior, $51,381-390$.

Spetch, M. L., \& Rusak, B. (1992). Temporal context effects in pigeons' memory for event duration. Learning and Motivation, 23, $117-144$.

Stanford, L., \& Santi, A. (1998). The dopamine D2 agonist quinpirole disrupts attention to temporal signals without selectively altering the speed of the internal clock. Psychobiology, $26(3), 258-266$.

Stubbs, D. A., \& Thomas, J. R. (1974). Discrimination of stimulus duration and $d$ amphetamine in pigeons: A psychophysical analysis. Psychopharmacologia, 36, 313-322.

Terrace, H. S., Gibbon, J., Farrell, L., \& Baldock, M. D. (1975). Temporal factors influencing the acquisition and maintenance of an autoshaped keypeck. Animal Learning and Behavior, 3, $53-62$.

Wolterink, G., Phillips, G., Cador, M., Donselaar-Wolterink, I., Robbins, T. W., \& Everitt, B. J. (1993). Relative roles of ventral striatal $D_{1}$ and $D_{2}$ dopamine receptors in responding with conditioned reinforcement. Psychopharmacology, 110, 355-364. 